\title{
Relaciones entre atacameños, arqueólogos y Estado en Atacama (norte de Chile) ${ }^{1}$
}

Patricia Ayala R. ${ }^{2}$

\section{RESUMEN}

A partir del caso atacameño se analiza cómo el patrimonio arqueológico y los discursos del pasado forman parte de los actuales movimientos de reivindicación étnica. Complementariamente, se discute cómo la patrimonialización étnica ha incidido en conflictos y reacomodos en las relaciones entre indígenas, arqueólogos y Estado en los últimos años. Para ello se asume una perspectiva teórico-metodológica que enfatiza el papel de las relaciones establecidas entre los actores involucrados y el proceso mediante el cual se conforma dicha interacción a lo largo del tiempo, recurriendo tanto a fuentes de información escrita como etnográfica.

Palabras claves: indígenas - arqueología - patrimonio - atacameños.

\section{ABSTRACT}

Based on the Atacameño case, this article analyzes how the archaeological heritage and the discourses about the past form part of current ethnic vindication movements. Complementary, it is discussed how in recent years processes of ethnic heritage appropriation have had impact in conflicts and the reshaping of relationships among indigenous people, archaeologists, and the state. For these purposes a theoretical-methodological perspective emphasizing the role of the relationships established among the involved actors and the process through which the mentioned interaction is formed through time is assumed, recurring to written and ethnographic sources.

Key words: indigenous - archaeology-heritage-Atacameño people.

Recibido: noviembre 2006. Aceptado: febrero 2007.

1 Este artículo es un extracto de la tesis de la autora para optar al Grado de Magíster en Antropología de la Universidad Católica del Norte y Universidad de Tarapacá.

2 Instituto de Investigaciones Arqueológicas y Museo R. P. Gustavo Le Paige s. j., Universidad Católica del Norte. Calle Gustavo Le Paige 380, San Pedro de Atacama, CHILE. Email: rayala@ucn.cl

\section{Introducción}

Desde los años 90 el Estado chileno se encuentra en un proceso de reconocimiento de la diversidad cultural, ya que dejó atrás el viejo discurso de identidad nacional orientado a controlar y suprimir las diferencias culturales, para adoptar una política multicultural y pluricultural que no sólo reconoce y promueve esta diversidad, sino que también la construye. Se trata de un nuevo contexto ideológico, legal e institucional en el cual cambiaron las relaciones del Estado con los pueblos indígenas, por lo que, de una política de negación, integración y asimilación de estas poblaciones -que caracterizó al Estado chileno desde su creación en el Siglo XIX hasta principios de los 90-, se pasó a otra de reconocimiento y promoción de las identidades étnicas con la promulgación de la Ley Indígena en 1993. Es así que, desde una posición de poder diferente a la de años anteriores, los indígenas emergieron como nuevos actores sociales, planteando una serie de demandas y luchas de significación y de poder en torno a sus derechos culturales y a los recursos existentes en sus territorios. En este contexto, ahora se cuenta con otro actor interesado en el patrimonio arqueológico y los discursos del pasado, el cual reivindica sus derechos y reclama su participación en el otorgamiento de sentido, producción y control de los mismos.

En otros países este fenómeno social ha sido abordado desde diferentes perspectivas en la discusión arqueológica, entre las cuales se cuentan aquellas que problematizan cómo el discurso arqueológico ha construido la imagen de los indígenas y en qué medida esto se vincula con el contexto social del investigador (Trigger 1992; Preucel y Hodder 1996), así como las referidas al tipo de relaciones establecidas con los pueblos originarios en la arqueología americana (Trigger 1980; Ferguson 1996; Bray 2001). Están también las discusiones en torno a la construcción de identidades étnicas en el pasado y sus implicancias y usos políticos en la actualidad (Trigger 1984, 1992; Jones 2001; Capriles 2003; 
Benavides 2004), los estudios que interpretan este contexto en torno a disputas de poder por el saber legítimo (Gnecco 1999, 2003 Ms, 2004) y los que lo analizan a partir del proceso de apropiación social del patrimonio (Endere 2002). En Chile, hasta hace pocos años este tipo de investigaciones estuvo ausente del debate arqueológico y antropológico ${ }^{3}$, a pesar de que las demandas patrimoniales planteadas por los indígenas y los cuestionamientos a la disciplina arqueológica se remontan a mediados de la década de los 90, posteriormente a la promulgación de la Ley Indígena. En efecto, son escasos los trabajos que abordan el problema de la visibilidad alcanzada por el patrimonio arqueológico en el proceso de emergencia étnica (Ayala 2004); además, a pesar de algunos intentos descriptivos (Ayala et al. 2003; Romero 2003; Uribe y Adán 2003), no se ha considerado el estudio de las relaciones establecidas entre los actores de este proceso como una forma de abordar este problema antropológico.

Un caso particularmente interesante en este sentido es el de la etnia atacameña en el norte de Chile, ya que sus líderes han planteado al Estado una serie de demandas de control, manejo y uso económico del patrimonio cultural. Asimismo, las investigaciones arqueológicas se iniciaron a principios del Siglo XX en la región atacameña y en los últimos años los líderes étnicos han planteado públicamente críticas a la arqueología. Paralelamente a esto, otra situación de interés es que el discurso étnico de los atacameños parece nutrirse tanto del discurso patrimonial difundido por el Estado como del discurso arqueológico, en circunstancias que las relaciones establecidas entre los actores de este proceso parecen variar a través del tiempo. Por ello, a partir del caso atacameño, en este artículo se aborda el problema de cómo y por qué el patrimonio arqueológico y los discursos del pasado forman parte de los actuales movimientos de reivindicación étnica, a la vez que ello contribuye de manera importante a dar forma y sentido al movimiento. Complementariamente, se discute de qué manera la patrimonialización étnica ha incidido en conflictos y reacomodos en las relaciones entre indígenas, arqueólogos y Estado, los últimos de los cuales históricamente han tenido

3 En Chungara, Revista de Antropología Chilena 35 (2), 2003, se publicaron 12 artículos que abordan esta temática y que forman parte de los resultados del "Encuentro de reflexión sobre patrimonio cultural, comunidades indígenas y arqueología” realizado en Ollagüe, Chile, el año 2001. una participación decisiva en la definición y control del patrimonio arqueológico.

Este trabajo centra su atención principalmente en el oasis de San Pedro de Atacama, aunque también considera información de la cuenca del Loa, ambos espacios ocupados por la etnia atacameña (Figura 1). Se trata de una investigación enfocada en el análisis de las relaciones establecidas entre los actores involucrados y en el proceso mediante el cual se conforma dicha interacción a lo largo del tiempo. Para ello se recurre tanto a fuentes de información escrita como etnográfica. La estrategia de análisis considera la definición de categorías de relaciones y de períodos históricos en los cuales se contextualizan las mismas.

De este modo, se establecieron seis categorías o tipos de relaciones que se observan como las más representativas de este proceso -negar, conocer, colaborar, visibilizar, dialogar/negociar y delegar/ intermediar-, la mayoría de las cuales incluye a los tres actores involucrados. ${ }^{4}$ Cabe mencionar que estas

4 El primer tipo de relación (negar) se refiere a que si bien se tiene un conocimiento de la existencia del otro, se lo deja de reconocer, no se admite su existencia. Se trata de una forma de interactuar que implica distanciamiento entre los actores, la inexistencia de relación y/o la exclusión del otro en lo que respecta a las prácticas asociadas a los materiales arqueológicos. Este tipo de relación ha sido practicada por arqueólogos y funcionarios estatales y, en los últimos años, por los atacameños. La segunda categoría (conocer) corresponde al establecimiento de relaciones a partir de las cuales los actores llegan a construir una relación y a reconocerse mutuamente. Son relaciones construidas a través del tiempo, en las cuales el compartir ciertos espacios sociales genera una conocimiento recíproco. De acuerdo al grado de interacción, esta forma de relacionarse permite un menor o mayor nivel de reconocimiento de los significados culturales, valoraciones e intereses del otro. A diferencia de la siguiente categoría, se trata de relaciones establecidas específicamente entre atacameños y arqueólogos. El tercer tipo de interacción (colaborar) se refiere a relaciones de trabajo en conjunto y se orienta a contribuir con conocimientos y prácticas a la consecución de un objetivo o proyecto relevante para los actores involucrados, apuntando así a una relación más recíproca y equilibrada entre las partes. Este tipo de relación se asocia al reconocimiento y valoración del aporte que el otro puede realizar al logro de un fin o proyecto en particular. La cuarta categoría (visibilizar) involucra a los tres actores de este proceso y se desarrolla desde la década de los 90, cuando se redefinen las relaciones del Estado con las poblaciones indígenas, pasando de una política de negación a otra de reconocimiento, visibilización y promoción de las identidades étnicas. El quinto tipo de interacción (dialogar/negociar) se refiere a la creación de un espacio de 


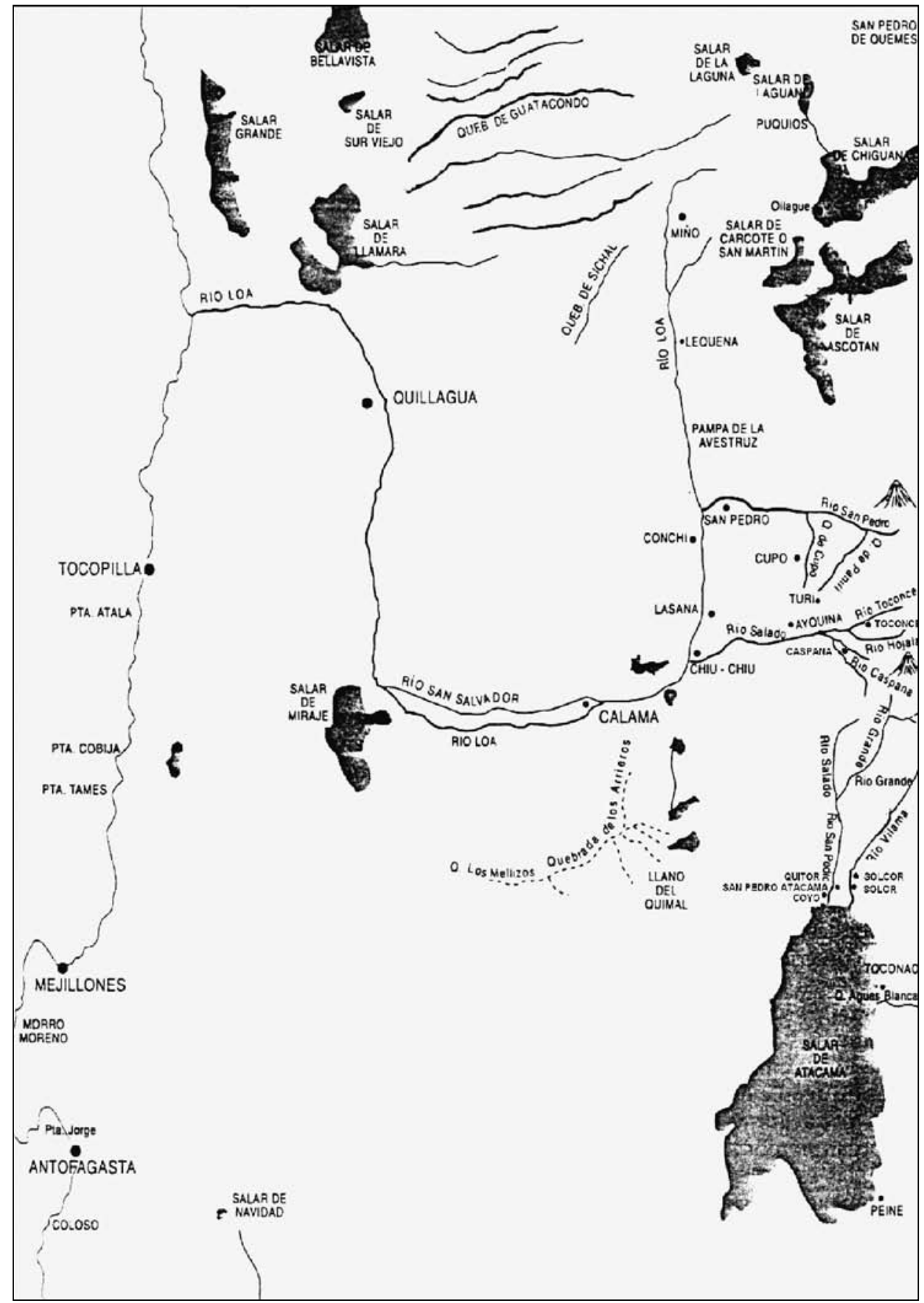

Figura 1. Mapa con los poblados atacameños de la cuenca del río Loa y el Salar de Atacama. Modificado de Castro y Martínez (1996).

diálogo entre los actores involucrados con el fin de construir una relación de valoración y legitimación mutua de sus discursos, así como de negociación entre sus significados culturales, valoraciones e intereses vinculados al patrimonio arqueológico. Esto se traduce en la realización de reuniones de discusión orientadas al tema patrimonial, organizadas tanto por indígenas como por arqueólogos o instituciones estatales. La sexta categoría (delegar/intermediar) corresponde a una modalidad de interacción en la cual un tercero se encarga de establecer relaciones entre arqueólogos y atacameños a través de la mediación de sus intereses con la finalidad de lograr un acercamiento y acuerdos entre ellos. 
categorizaciones, al tratarse de relaciones humanas, tienen diferentes matices en su interior y por lo mismo sus límites se superponen en algunos casos. Son formas de relacionarse que pueden ser practicadas por un mismo actor o por diferentes actores a la vez, pudiendo darse de manera sincrónica o diacrónica en el tiempo. Asimismo, se definieron tres períodos históricos en base a la articulación de las siguientes variables: el tipo de relaciones establecidas entre las poblaciones indígenas, los arqueólogos y el Estado chileno, la existencia o no de una adscripción étnica atacameña, el desarrollo del proceso de patrimonialización en el país y la profesionalización de la arqueología chilena. A continuación se presentan los resultados de esta investigación a partir de los períodos identificados.

\section{El proceso de interacción entre atacameños, arqueólogos y Estado en Atacama}

\section{Período 1: Finales del siglo XIX hasta la década del 70}

Este período se caracteriza por la negación del sujeto indígena de parte del Estado chileno en un contexto en el cual los atacameños son tratados como cualquier ciudadano, en circunstancias que "una condición de indígena no tenía significado político para la relación entre el Estado chileno y las comunidades campesinas de base agraria de esta zona" (Gundermann 2002 Ms: 22). Esta relación de negación desde el Estado se prolonga hasta principios de la década del 90, paralelamente a un proceso de asimilación e integración de la población indígena.

En estos años, los habitantes de la cuenca del Loa y del Salar de Atacama no se identificaban con la adscripción étnica de atacameños sino más bien con identidades locales, además de vincularse de manera contradictoria y conflictiva con la noción de indio, ya que conllevaba atributos negativos de atrasado, incivilizado, marginal, sin educación. Esto es el resultado de un proceso en el cual a finales del Siglo XIX y principios del XX "la idea de indio pierde esa condición irrenunciable, esa condición de estatus adscrito, ese ropaje que se tiene desde el momento en que se nace, verdadera piel que se tiene y que no se puede sacar" (Gundermann 2002 Ms: 32).

En 1925 se crea el Consejo de Monumentos Nacionales (en adelante CMN), por el Decreto de Ley $\mathrm{N}^{\circ} 651$ que rigió hasta 1970 cuando se promulga la Nueva
Ley de Monumentos Nacionales. Si bien este decreto tenía cuatro ámbitos de acción referidos a definir los monumentos históricos, los monumentos públicos, las excavaciones arqueológicas y el registro e inscripción de museos, el funcionamiento de esta institución fue bastante irregular y, al parecer, su presencia en otras regiones casi nula. A lo largo de estos 45 años el CMN sólo declaró 50 monumentos históricos, lo cual sin duda evidencia un discurso patrimonial en ciernes, lejos de tener la envergadura del actual. Además, los monumentos declarados correspondían en su gran mayoría a iglesias, fuertes y edificios públicos, lo cual demuestra una concepción del patrimonio nacional análoga a la de países europeos. Si bien el desarrollo de investigaciones arqueológicas era de interés estatal, el control sobre las excavaciones y los responsables de las mismas, en circunstancias que la formación profesional en arqueología se produciría recién en los años 60 y 70, fue prácticamente nulo en este período.

Desde principios del Siglo XX, acorde al discurso modernizador del Estado chileno, se desarrolla una importante actividad científica en la región atacameña. Llegan equipos extranjeros como la Misión Científica Francesa integrada por De la Grande, De Créqui-Montfort y Boman, que desarrollan investigaciones arqueológicas y etnográficas en la zona. Del mismo modo, el gobierno contrata a Max Uhle, arqueólogo y etnólogo alemán, quien realiza investigaciones arqueológicas y reconstrucciones históricas, desde la prehistoria hasta la actualidad, en el norte del país. Esto fue particularmente importante en el territorio atacameño, recientemente anexado al Estado de Chile, ya que el proyecto de identidad nacional requería la construcción de una historia que abarcara los orígenes prehispánicos de los habitantes de esos territorios. Según Gundermann y González (2005 Ms: 2), en estos momentos "la antropología ya no es una actividad tangencial o circunstancial, sino una preocupación científica con importancia política", la cual tiene una orientación principalmente histórica, dentro de la cual se pueden situar también las posteriores investigaciones de Latcham en la región atacameña.

En este período no existía una conciencia social o un tipo de valoraciones que permitiera reconocer y relacionarse con los indígenas como actores sociales, ya que no sólo el Estado y la sociedad chilena los negaba, sino también ellos mismos. En el ámbito de la antropología y la arqueología estas poblaciones eran consideradas como objetos de estudio, como 
reminiscencia de un pasado que es importante conocer antes de que desaparezca. Si bien los intereses de los estudiosos de esta época eran eminentemente científicos, sus resultados adquieren un sentido político ya que "su balance de la situación del indígena nortino (...) señala su completa integración (changos) o la presencia de escasos supervivientes y en franco proceso de asimilación (aymaras y atacameños)" (Gundermann y González 2005 Ms: 2). De este modo, los resultados de las investigaciones científicas apoyan y justifican la política nacional de negación, integración y asimilación de los pueblos indígenas. Es así que el sentido político que se le otorga a las investigaciones arqueológicas en Chile es similar al identificado en la construcción de los Estados-nación del Viejo Mundo, donde el conocimiento del pasado prehistórico alimentó los discursos de identidad de las nuevas naciones.

Coherentemente con el contexto político, social y profesional de la época, la práctica arqueológica en Atacama debió caracterizarse por una relación de poder marcadamente asimétrica con los indígenas, quienes desde una posición de subordinación cumplieron un rol de obreros y/o de informantes, más aún considerando que los arqueólogos se vinculaban a intereses estatales y/o privados, y se trataba de extranjeros o santiaguinos profesionales asociados a la clase dominante. Una relación mucho más compleja con los atacameños es la que estableció el sacerdote y arqueólogo aficionado Gustavo Le Paige, ya que, a diferencia de otros estudiosos que trabajaron en la zona en este período, él vivió en San Pedro de Atacama durante 26 años, generando así una red de interacciones que delinearemos a continuación. ${ }^{5}$

La población indígena que Le Paige encuentra a su llegada en 1954 es una sociedad que si bien mantiene una serie de prácticas y discursos enmarcados en la tradición andina, también vivencia un proceso de cambios relacionados con su inserción en la economía y sociedad regional. Dentro lo que se puede considerar parte de la tradición local, se identifican las valoraciones vinculadas con el respeto y temor a los "abuelos" o "gentiles", entidades de otra humanidad que se asocian a los vestigios arqueológicos.

5 Es importante considerar que la figura de Le Paige es vista y evaluada por los atacameños desde una conciencia y valores actuales, no obstante, es posible perfilar las formas de relación que estableció sin desconocer el contexto político y social en el cual se desarrollaron.
Le Paige inicia su labor arqueológica cuatro años después de llegar a esta zona como sacerdote, comenzando poco tiempo después la creación de lo que actualmente es el Museo Arqueológico de San Pedro de Atacama, en circunstancias en que paulatinamente se familiariza con las particularidades culturales de la población local. ${ }^{6}$

El desacuerdo o crítica generalizada de los atacameños al referirse a la labor arqueológica de Le Paige se vincula con su excavación de cientos de tumbas, lo cual visto desde las prácticas y discursos locales de la época estaba en contra de sus valoraciones y creencias (Figuras 2 y 3 ). En efecto, los atacameños se refieren a los sitios arqueológicos como lugares y obras de los "abuelos", de los "gentiles", espacios $\mathrm{y}$ cosas que hay que respetar y temer, en los cuales puede "pescarte la tierra" o pueden "agarrarte los abuelos" y producirte enfermedades, por lo que es mejor no molestarlos, no visitarlos ni tomar nada de allí:

"uno de los, de los valores, como es el respeto de los abuelos, por ejemplo, o a los abuelos, a todos sus enterramientos... En cuanto a la familia le entregaba este valor de, por una parte no tocar, y cuando se encontraran objetos de volver a ponerlos en su lugar de origen y dejarlos ahí con el descanso que inicialmente se dispuso en ese lugar" (Atacameño 1, 2004). ${ }^{7}$

En estas circunstancias, las excavaciones de Le Paige fueron vistas como una "falta de respeto" a las creencias locales, sobre todo teniendo en cuenta que este sacerdote llegaba con "la camioneta cargada" todos los días después de excavar. Lo anterior se interpreta como una negación de parte de Le Paige del significado cultural que esto tenía para los atacameños, ya que a pesar de conocer las valoraciones vinculadas a los "gentiles", su interés científico por la prehistoria atacameña lo llevó a negar los discursos y prácticas contemporáneas de la población local. Esto no sólo es coherente con el contexto político y el desarrollo de la arqueología de ese entonces, sino también con su práctica sacerdotal dentro de la cual debió con-

6 Si bien este Museo forma parte del Instituto de Investigaciones Arqueológicas y Museo (IIAM) de la Universidad Católica del Norte, en adelante me referiré a él como el Museo, el Museo local o el Museo de San Pedro de Atacama, ya que, en general, así lo denominan los actores involucrados.

7 A solicitud de la mayoría de los entrevistados no se dan a conocer sus nombres e iniciales. 


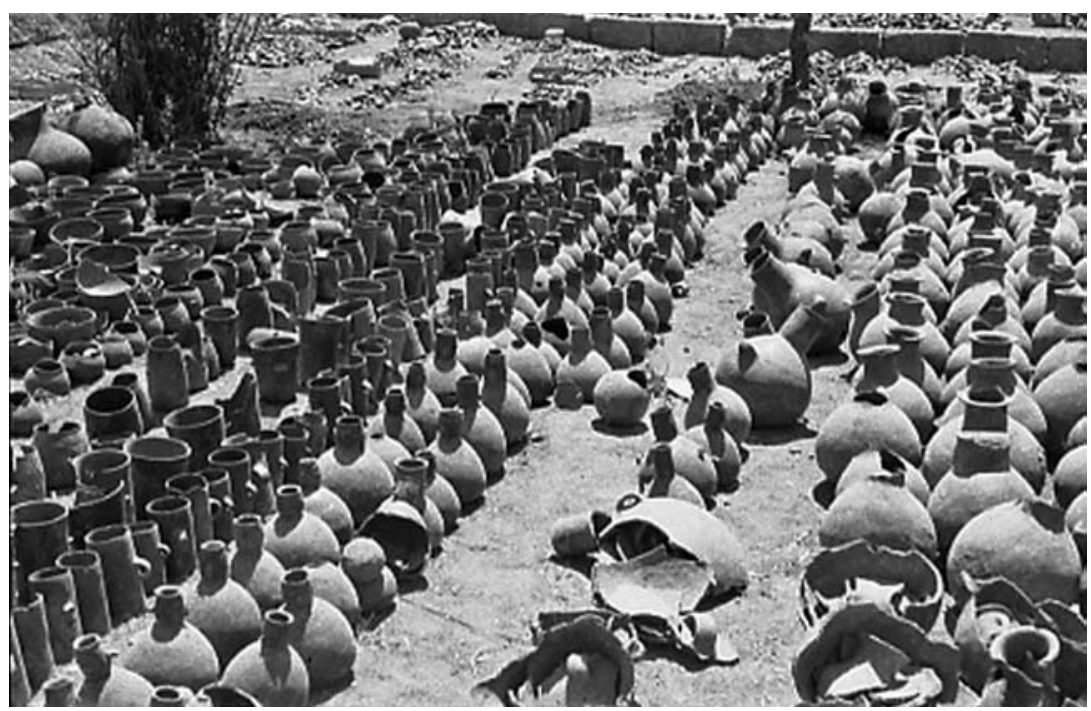

Figura 2. Colección de cerámica obtenida en las excavaciones de Le Paige (décadas del 60 y 70). Archivo IIAM.

siderarse importante erradicar estas creencias. Al respecto, uno de sus ayudantes atacameños plantea que este sacerdote con sus excavaciones "quería dar a conocer que los gentiles no hacían nada", lo cual

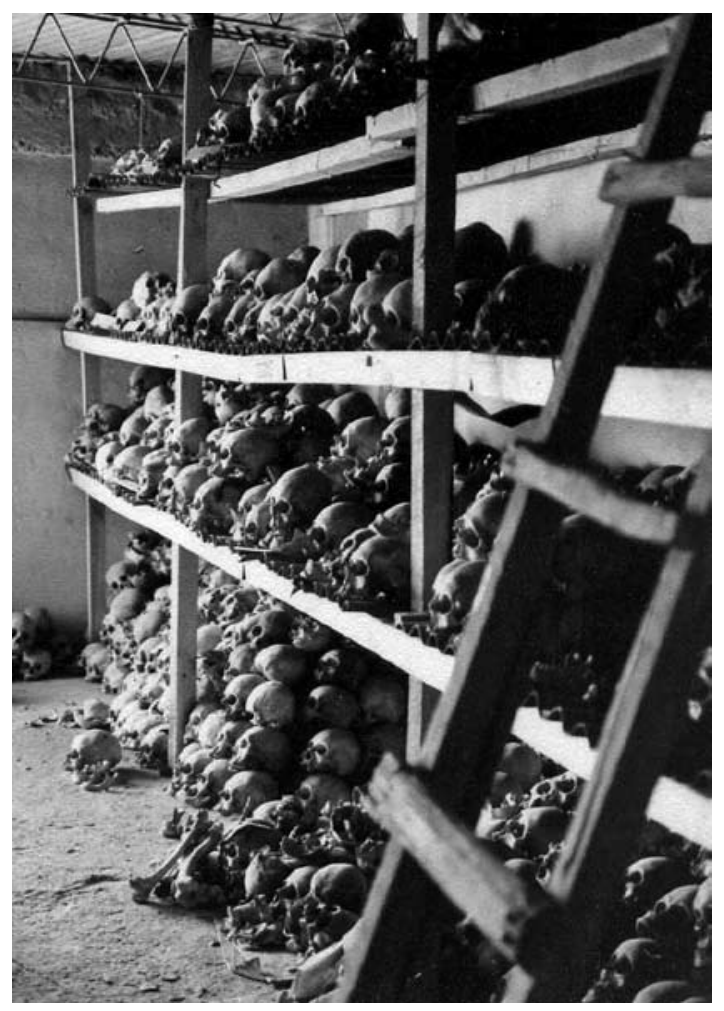

Figura 3. Colección de cráneos obtenida en las excavaciones de Le Paige (décadas del 60 y 70). Archivo IIAM. es particularmente interesante si se considera que el temor a los "abuelos" puede ser producto de la acción cristiana, ya que, de ser así, Le Paige negó una creencia impuesta por su religión en su propio afán de extirpar idolatrías.

Teniendo en cuenta el poder de Le Paige como autoridad científico-religiosa y en un ambiente social y político desfavorable para los indígenas, era difícil que los atacameños que así lo creían expresaran su desacuerdo respecto de las excavaciones de cementerios arqueológicos: "con el padre Le Paige mucha gente se alejó de la iglesia cuando empezó a trabajar la parte arqueológica, por lo mismo, porque, bueno, el padre no ocultaba tanto lo que tenía, él tenía muchos cráneos" (Atacameño 2, 2003). Ciertamente, para que la gente "dejara de ir a misa" tuvo que ser muy fuerte el descontento de la población local, ya que esto no sólo implicó un acto de reprobación de la labor arqueológica de Le Paige, sino también un distanciamiento de su religión. El desacuerdo de los atacameños se mantuvo sobre todo en el ámbito de lo privado, en conversaciones entre ellos, en un espacio familiar en el cual algunos niños que acompañaban al padre en sus excavaciones eran reprendidos e incluso obligados a devolver lo que tomaron de los "abuelos", para posteriormente hacer un "pago" u ofrenda a los mismos. Asimismo, se plantea que a pesar del respeto que se le tenía como sacerdote:

"había gente que estaba indignada con él pero también, no sé si lo manifestaba o se lo manifestaba 
de alguna forma un poco suave o de formas muy distintas que lo hicieran repensar su actitud en cuanto al trabajo que estaba desarrollando como arqueología" (Atacameño 1, 2004).

Se dice que este sacerdote tenía "licencia para hacer o decir cualquier cosa sin que nadie le dijera nada", ante lo cual se plantea que:

"en ese tiempo el padre Le Paige era una autoridad, entonces no se le podía contradecir. Tal vez a lo mejor esa era una de las causas que la gente tampoco no le decía nada. Pero si el padre Le Paige hubiera estado en estos días, tal vez hubiera sido diferente. Pero en ese tiempo se le tenía mucho respeto al padre Le Paige. Incluso en algunos extremos yo creo que tal vez miedo" (Atacameño 8, 2004).

Se manifiestan opiniones negativas respecto a Le Paige, ya que se dice que se aprovechó de su autoridad religiosa y de las necesidades de la población local para recibir información, que "robó" su patrimonio, que los "engañó":

"En parte me dicen cosas que, como que él los engañaba. Como el hecho de que él les preguntaba por un sitio y la gente a veces por necesidad - muchas veces comprensivo-le decía del lugar, le hablaba del lugar, y él le daba, qué sé yo, harina" (Atacameño 8, 2004).

Contemporáneamente a la labor arqueológica de Le Paige en la cuenca del Loa trabajaron otros profesionales y aficionados de la arqueología, los cuales a diferencia de este sacerdote no son identificados por sus nombres, sino generalmente como "gringos". Un ejemplo es el arqueólogo francés J. Spahni que excavó cementerios prehispánicos en Chiu Chiu, Lasana y Turi, así como el ingeniero De Bruyne que excavó el Cementerio de los Abuelos en Caspana. El caso de Chiu Chiu es particularmente importante de comentar, ya que los cementerios de esta localidad, además de las investigaciones arqueológicas realizadas en esa época por Mostny y Spahni, fueron objeto de reiteradas excavaciones a cargo de aficionados que trabajaban en la mina de cobre de Chuquicamata, algunos de los cuales incluso usaron dinamita para extraer materiales arqueológicos. En una época en que las excavaciones arqueológicas en la zona, en general, no se realizaban de acuerdo a una metodología fina, la labor arqueológica se percibió como una actividad similar al saqueo. Esta imagen fue, sin duda, fortalecida con el tipo de excavaciones realizadas por Le Paige, y en la actualidad es utilizada por los atacameños para criticar a la disciplina.

Sin embargo, paralelamente a la negación de los significados culturales de los atacameños, como sacerdote y líder comunitario Le Paige estableció relaciones de conocimiento y cercanía con la población local, ya que participó, compartió y se involucró en una serie de actividades de la comunidad, siendo incluso promotor de algunas de ellas (L. Núñez 1995). En este contexto, a pesar de los desacuerdos existentes con su quehacer arqueológico, la gente no dejó de apoyarlo en obras de beneficio social. Esta forma de relacionarse de Le Paige se vincula con opiniones positivas hacia su persona, las cuales siempre están mediadas por su rol como sacerdote del pueblo. Es así que se describen relaciones de cercanía y confianza con él, de amistad, compadrazgo y afecto, las cuales permiten comprender cómo en la actualidad atacameños de edad avanzada que participan en las ceremonias de conmemoración de su natalicio o muerte, se emocionan al recordarlo y hablar de su obra social y sacerdotal.

Otro tipo de relación establecida por Le Paige con los atacameños fue de colaboración, ya que en reiteradas ocasiones trabajó en conjunto con la población local para el logro de fines o proyectos de relevancia social (p.e., implementación de un consultorio médico). La relación establecida con sus ayudantes atacameños también podría enmarcarse dentro de este tipo de interacción, aunque es diferente a lo observado en períodos posteriores cuando los arqueólogos aportan al otro desde sus prácticas y conocimientos profesionales. En este caso un grupo de atacameños colaboró, como informantes y ayudantes de terreno, en el quehacer arqueológico de Le Paige, mientras éste ayudó a ese grupo desde el punto de vista social.

Como se pudo observar, en este período se identifican distintas formas de interacción entre arqueólogos e indígenas: negar, conocer y colaborar, las cuales en algunos casos son activadas por los mismos sujetos sociales. Esto se desarrolla en un contexto de negación de las poblaciones indígenas de parte del Estado chileno y de un discurso patrimonial en ciernes.

\section{Período 2: Década del 70 hasta 1993}

En 1970 se promulga la Nueva Ley de Monumentos Nacionales $\mathrm{N}^{\circ} 17.288$, con lo cual cambia sustan- 
cialmente el funcionamiento del CMN, así como se consideran nuevas categorías de monumentos y se establece que los sitios y objetos arqueológicos son monumentos arqueológicos del Estado chileno sin la necesidad de ser declarados como tales. Desde ese entonces se evidencia una mayor actividad y sistematicidad en el accionar del CMN, así como se incrementa sustancialmente la cantidad y diversidad de declaratorias. En este período, el discurso patrimonial del Estado comienza a fortalecerse y diversificarse, considerando entre los monumentos declarados también bienes arqueológicos y paleontológicos. Este cambio en la institución y legislación patrimonial coincide con la creación de departamentos y carreras de arqueología y antropología en diferentes universidades del país: el Departamento de Ciencias Antropológicas y Arqueológicas y la Licenciatura en Antropología en la Universidad de Chile, la carrera de Arqueología en la Universidad del Norte, el Departamento de Antropología en Arica y la carrera de Antropología en Concepción (Castro 1995; Orellana 1996; Romero 2003).

En 1973 se produce el golpe militar y en este nuevo escenario político el Estado chileno continuó con la misma forma de relacionarse con los indígenas, es decir, negándolos. Según Gundermann (2002 Ms: 51):

"al gobierno autoritario no le interesó la figura del indio, salvo para negarlo (...) Lo étnico se relega a lo folklórico, se relega al pasado (...) se especifica en una herencia cultural que hay que poner en un museo, (...) representar eventualmente, (...) documentar por escrito, pero no tiene sentido presente, ni tampoco sentido futuro".

Según este autor, durante el gobierno militar se refuerza la idea de una identidad nacional basada en una comunidad única que no deja espacio a la población indígena. En este sentido, es interesante considerar que entre 1970 y 1994 se produce un incremento inusitado en la declaración de monumentos nacionales, el cual alcanza a 509 declaratorias, lo cual sin duda se relaciona con este discurso de identidad nacional exacerbado.

Si bien el gobierno autoritario tuvo una serie de consecuencias en las ciencias sociales, como la disminución de la planta académica del Departamento de Antropología y Arqueología de la Universidad de Chile y la desaparición de las carreras de Antropología en la Universidad de Concepción y de Arqueología en la Universidad del Norte (Castro 1995; Romero 2003), además de la persecución de profesionales de estas carreras, la arqueología continuó desarrollándose en el país con repercusiones al parecer menos desarticuladoras que las vivenciadas por disciplinas cercanas. Esto parece deberse a que la arqueología fue percibida por el gobierno como una práctica más neutra, más científica y menos política que la antropología o la sociología, lo que explicaría el hecho de que se mantuviera por algún tiempo la Escuela de Antropología de la Universidad del Norte, con menciones en arqueología y antropología sociocultural, pero "después de muchos intentos, sólo se aceptó que siguiera como carrera [la disciplina de la] arqueología, [pero] con un cierre inevitable" (Castro 1995: 20). Junto con esto, para el proceso de fortalecimiento de la identidad nacional de la época, era necesario continuar con el estudio de los orígenes de esta comunidad imaginada, sobre todo en territorios fronterizos donde urgía una mayor presencia del Estado, como en la región atacameña, con lo cual se relaciona también el desarrollo de estudios antropológicos en la región andina.

Paralelamente, las poblaciones indígenas de la cuenca del Loa y del Salar de Atacama continúan identificándose con adscripciones locales y vinculándose de manera conflictiva y contradictoria con la identidad de indio, en un escenario en el cual los discursos étnicos no tienen relevancia política para el Estado y las propias poblaciones indígenas. Durante este período, por su carácter fronterizo, la región atacameña es enfocada geopolíticamente por el gobierno militar, el cual aplica una serie de medidas para retener a la población local en los marcos del modelo de desarrollo neoliberal, para lo cual solicita diagnósticos a antropólogos, sociólogos y otros profesionales (Gundermann y González 2005 Ms). En estas circunstancias:

"el indígena es percibido como un sujeto pasivo, atrasado y pobre, que debe recibir el apoyo estatal para sobrevivir, para modernizarse y progresar económicamente. Para lograr este objetivo, el Estado debe acercar el progreso y el cambio al sector rural, de manera que esta población no abandone sus zonas interiores" (Gundermann y González 2005 Ms: 6).

Es así que la relación del Estado con las poblaciones indígenas sigue siendo de negación, asimilación e integración. 
En este panorama nacional, Le Paige continuó con su quehacer arqueológico en la región atacameña, mientras los arqueólogos nacionales y extranjeros desarrollaban investigaciones en el Salar de Atacama y la cuenca del Loa, algunos manifestando su desacuerdo con las excavaciones de este sacerdote (L. Núñez 1995). Si bien en estos momentos ya se consideran una mayor diversidad de tipos de sitios y temas de estudio, en San Pedro de Atacama sigue la tendencia por la arqueología funeraria, además de profundizarse la investigación sobre el período de influencia Tiwanaku. En efecto, después de la muerte de Le Paige en 1980, con una metodología y problemas de investigación propios de una arqueología profesional y sin la envergadura alcanzada en tiempos previos, se continuó con la excavación de cementerios prehispánicos en el oasis, frente a lo cual la población san pedrina tampoco manifestó públicamente su desacuerdo: "Pero cuando nosotros llegamos seguimos una tradición que había sido empezada por Le Paige, y [los atacameños] siguieron la misma actitud, no les gustaba pero qué iban hacer" (Arqueólogo 6, 2004).

En este contexto, los arqueólogos siguieron negando el valor local asignado al respeto y temor a los "abuelos", lo cual coexistía con una relación problemática y contradictoria de los atacameños con la noción de los lugares y obras de los "abuelos" como "cosas de indios", ya que una cosa era respetar y temer a estas entidades y otra diferente, identificarlas como antepasados. Esto debió generar tensión con los arqueólogos, ya que por un lado la población local negaba su vínculo con los materiales arqueológicos y, por otro, los arqueólogos se encargaban de difundir que los atacameños eran descendientes de las sociedades prehispánicas: "si lo que hay dentro del Museo era de los indios y yo les estaba diciendo que ellos eran los descendientes y herederos de esa tradición, yo les estaba en la cara llamando indios" (Arqueólogo 6, 2004).

Esta relación de negación se vincula además con la idea de que el Museo de San Pedro de Atacama era un espacio "cerrado", sin participación de la comunidad, aunque los atacameños coinciden en que es necesario diferenciar las relaciones personales de las institucionales. Para los arqueólogos de la época esta institución también era un lugar "cerrado" para la comunidad: "Entonces era una cosa cerrada que algunos entraban, salían, que trabajaban acá, pero los demás no tenían idea y tampoco estaban muy interesados en saber lo que había" (Arqueólogo 6, 2004). Se cuenta que desde tiempos de Le Paige este Museo era mirado con desconfianza y que incluso ciertos miembros de la comunidad "odiaban a los del Museo" y prohibían la entrada de su familia a ese lugar. Esto podría relacionarse con que la presencia de "tanto abuelo" en el Museo se visualizaba como un motivo por el cual personas de la comunidad, sobre todo gente adulta, no lo conocieran, no quisieran conocerlo o lo visitaban con reticencia: "mucha gente no iba al Museo. Me acuerdo que mi tía... entraba con el agüita bendita, iba primero a echarle agua bendita a las momias. Porque la gente tenía recelo al Museo" (Atacameño 3, 2004).

Los últimos años de la década del 80 se describen como particularmente problemáticos en cuanto a las relaciones con la comunidad local, además de existir dificultades entre profesionales del Museo y arqueólogos externos a esa institución. Respecto a las relaciones con la población indígena se plantea:

"ahí fueron por lo menos 10 años de tormento, de locura. De tormento realmente. Yo llegué a pensar que el $80 \%$ del pueblo estaba en contra de nosotros y el $20 \%$ restante era indiferente. No estaba ni ahí con el asunto... Ese período que te estoy hablando de fines de la década del 80 . Y yo pensaba que no valía de nada todo el esfuerzo que yo había hecho porque las cosas no mejoraban, estaban peores y la actitud de los atacameños, a la vez de empezar aceptar su atacameñeidad, más la rechazaron" (Arqueólogo 6, 2004).

Lo expuesto hasta el momento muestra una parte del sistema de relaciones establecidas en este período, ya que tanto atacameños como arqueólogos reconocen que también hubo otro tipo de relaciones, sobre todo a principios de los años 80, las cuales se vinculan con la participación de miembros de la comunidad en actividades organizadas por profesionales del Museo:

"Mira, yo creo que fue una relación muy bonita, al menos yo tuve buenas experiencias pero yo, de esto estoy conversando puede ser el año 82, que llegaron [los arqueólogos]...ellos trabajaban en realidad por el pueblo, se entregaban bastante al pueblo, que ahora eso no lo hacen yo no sé, cuál ha sido que se han alejado mucho, también, después no he estado mucho en contacto, pero de primera, cuando ellos llegaron hicimos muchas cosas buenas..." (Atacameño 2, 2003). 
Un aspecto importante de esta relación de conocerse entre arqueólogos y atacameños es que la participación en el quehacer arqueológico de parte de estos últimos generó una mayor defensa y percepción positiva de la labor realizada por los primeros:

"la gente siempre decía lo mismo, que los arqueólogos se robaban las cosas valiosas y yo sabía que no era así porque yo siempre tuve buenos contactos con los arqueólogos y ellos me mostraron que todo estaba guardado, entonces fue bueno a las finales porque también se le dijo a la gente que estaba todo" (Atacameño 2, 2003).

Esta apreciación es formulada por una dirigente que lideró la formación del Comité de Defensa del Patrimonio Cultural de San Pedro de Atacama, organización que fue constituida a partir de una relación de colaboración entre arqueólogos y atacameños. Es así que en este período se encuentra instalada una conciencia patrimonial en esta localidad, a partir de la cual se habla de "nuestro patrimonio" o de un "patrimonio del pueblo", además de nombrarse delegados del Comité en cada ayllu y comuna para controlar el saqueo. En este contexto, se plantea que "todo lo que hay aquí nos pertenece, son legado de nuestros antepasados y deben permanecer por lo tanto aquí en nuestra tierra" (El Mercurio, Calama, 30 de mayo de 1991). Esto muestra que desde una situación de negación del vínculo con los vestigios arqueológicos a finales de este período se pasa a otra de identificación de éstos como obras de los antepasados de los habitantes del oasis de Atacama.

Por otro lado, en la cuenca del Loa el discurso patrimonial se instala más tardíamente, ya que no se contaba con un organismo o comité que impulsara y sistematizara las acciones en este sentido. A diferencia de los oasis, los arqueólogos que trabajaban en este sector no radican en la zona, razón por la cual el proceso de apropiación e interiorización de este discurso por parte de la población local debió ser más lento. Otra distinción entre ambas zonas es el énfasis en la arqueología de asentamientos y períodos prehispánicos tardíos en la cuenca del Loa, a lo cual es importante agregar la realización de investigaciones etnoarqueológicas, inexistentes en los oasis. Junto con esto, es con las investigaciones en el Loa que se comienza a cuestionar la unidad cultural atacameña y la adscripción étnica del registro arqueológico, poniéndose especial atención al desarrollo prehispánico a nivel local.
En la localidad de Toconce, arqueólogos de la Universidad de Chile realizan investigaciones etnoarqueológicas a finales de la década del 70 , iniciándose así no sólo una nueva línea de trabajo en la región atacameña, sino también una forma diferente de interacción entre arqueólogos e indígenas, en los marcos de investigaciones que integran a la etnografía en sus problemas y objetivos. En estas circunstancias, las percepciones indígenas de la práctica arqueológica fueron consideradas a la hora de elegir los temas y metodologías, ya que a lo largo del proceso investigativo se identificaron aprensiones de algunos habitantes de Toconce sobre las excavaciones arqueológicas:

"había una señora que...llegaba a vernos y decía 'qué están hurgando ustedes ahí, qué están hurgando'. O sea, a ella no le parecía bien y ella lo manifestaba y yo pienso que muchas personas de Toconce, a lo mejor, no les parecía tan bien lo que estábamos haciendo, pero no se atrevían a manifestarlo" (Arqueólogo 1, 2004).

Se plantea que, en general, hubo buenas relaciones con la comunidad, aun cuando sus miembros no entendían o aprobaban todo lo que estaban haciendo. En este sentido, a pesar de una relación de cercanía y participación en actividades de la comunidad, se mencionan ciertos desacuerdos con la labor arqueológica, indicando que este tipo de relación no necesariamente implica la aceptación de esta práctica, lo cual parece relacionarse con la valoración al respeto a los "abuelos" y a las creencias mortuorias de esta localidad (Aldunate y Castro 1981; Berenguer et al. 1984).

Como se puede apreciar, en este período se identifican distintas formas de interacción entre arqueólogos e indígenas: negar, conocer y colaborar, las cuales se desarrollan en el marco de un proceso de profesionalización de la disciplina arqueológica, de fortalecimiento del discurso patrimonial a nivel nacional y de negación del sujeto indígena de parte del Estado chileno.

\section{Período 3: 1993 hasta la actualidad}

A finales de la década del 80 el tema de los pueblos indígenas es abordado por la Concertación de Partidos por la Democracia, la cual se compromete a crear una Comisión Especial de Pueblos Indígenas encargada de proponer su reconocimiento constitucional y promover una legislación que favorezca su 
desarrollo. Así, se elabora una propuesta de ley que posteriormente se promulga en 1993 (Ley Indígena $\mathrm{N}^{\mathrm{o}} 19.253$ ), produciéndose un cambio en la relación del Estado con las poblaciones indígenas. De este modo, desde contextos históricos de negación y asimilación de estas poblaciones, se pasa a una política de promoción y reconocimiento de los indígenas de parte del Estado chileno. Con ello, se crea la Corporación Nacional de Desarrollo Indígena (en adelante CONADI), uno de cuyos objetivos es la conservación y desarrollo del patrimonio cultural indígena, por lo cual cuenta con un área dedicada al patrimonio, evidenciando así la relevancia de éste en el discurso étnico promovido por el Estado.

A mediados de la década del 90 se inicia una mayor consolidación del CMN, lo cual repercute en el incremento y fortalecimiento del proceso de patrimonialización en el país, así como en la mayor relevancia y ampliación del concepto de patrimonio. En efecto, con la Nueva Ley de Monumentos Nacionales se incrementa considerablemente la naturaleza y el número de bienes protegidos como tales, observándose que desde 1994 hasta la fecha se ha duplicado el número de declaratorias. En estas circunstancias, el Estado asume más claramente que nunca su rol protagónico en la definición, sistematización, institucionalización y control del patrimonio cultural del país. Asimismo, el CMN desarrolla una política de participación ciudadana, dentro de la cual, entre otros, se aborda el tema indígena, inaugurándose el año 2001 el área de Patrimonio Cultural de los Pueblos Indígenas. Esto avala la preocupación del Estado por incluir el patrimonio indígena como parte del patrimonio nacional, además de su interés por ejercer el control de estos bienes y enfatizar la propiedad estatal de los mismos. En este período, el discurso estatal no sólo promueve la protección, conservación y difusión del patrimonio, sino también la ejecución de proyectos de puesta en valor y manejo de sitios arqueológicos por parte de las comunidades indígenas, invirtiéndose importantes capitales.

Por otro lado, en los primeros años de este período la arqueología escasamente se preocupa en vincularse con la sociedad en general, lo que es evidente en los congresos nacionales de arqueología y en las publicaciones donde esta temática está prácticamente ausente, con la excepción de algunos trabajos. Esto parece deberse, entre otras cosas, a las características de la malla curricular de la Carrera de Arqueología de ese entonces, en la cual en ninguna materia se desarrollan temas como las repercusiones sociales del discurso arqueológico, la influencia del contexto sociohistórico en la construcción del pasado o la necesidad de difundir los resultados de las investigaciones. A ello se podría sumar la vigencia del enfoque histórico cultural y la orientación marcadamente positivista que ha caracterizado a la arqueología chilena (Salazar y Jiménez 1999), sin que con esto se pretenda desconocer una serie de trabajos orientados por otras corrientes teóricas pero que no constituyen la tendencia general. En estas circunstancias, la problemática relacionada con las comunidades indígenas prácticamente no ha ocupado, sino hasta hace poco, un espacio de reflexión y discusión en la arqueología chilena (p.e., Navarro 1998; Chungara, Revista de Antropología Chilena 35 [2], 2003).

En cuanto al proceso de construcción de una conciencia atacameña, el giro producido por el Estado hacia una valoración positiva del concepto de indio conllevó un proceso de asumirse como indígenas y sentirse parte de esta etnia, lo cual no estuvo exento de conflictos, ya que inicialmente algunas personas no estaban dispuestas a definirse como indígenas: "hicimos un plebiscito acá, porque me acuerdo yo, porque la gente no quería que los nombraran indios, que la Ley debería llamarse cualquier cosa menos Ley Indígena" (Atacameño 3, 2004). A esto se suma que fue necesario integrar en un proyecto étnico común a poblaciones del Salar de Atacama y cuenca del Loa, las cuales hasta ese entonces se identificaban con sus localidades de origen y de forma problemática con la noción de indio, pero no con la adscripción étnica de atacameños con la cual se relacionan actualmente con el Estado chileno.

Cabe mencionar, además, que la inserción de los atacameños en la Ley Indígena se produjo sólo después de la movilización de líderes y agrupaciones indígenas, organismos gubernamentales y no gubernamentales (ONGs), la iglesia, y profesionales de diferentes disciplinas, aunque los dirigentes atacameños destacan el aporte de miembros de las propias comunidades. Respecto a la participación de otros actores, se describen relaciones de colaboración entre atacameños y profesionales de las ciencias sociales en las gestiones realizadas para su reconocimiento ante el Estado. En efecto, los atacameños, al no estar incluidos como uno de los pueblos originarios en el borrador de la Ley Indígena, reunieron antecedentes para validarse como etnia. Uno de esos antecedentes fue la información ar- 
queológica que avaló la profundidad de sus raíces en el tiempo. En la recopilación de ésta trabajaron en conjunto atacameños y profesionales del Museo de San Pedro de Atacama. De este modo, para legitimarse ante el Estado los atacameños utilizaron y reivindicaron el discurso de continuidad histórica, planteamiento que fuera postulado por Le Paige desde la década del 50 y retomado posteriormente por otros arqueólogos de la zona.

Por otro lado, la adopción del apelativo de atacameños parece haber sido tomada del discurso científico. A principios del Siglo XX esta denominación fue utilizada por Uhle para referirse a ocupaciones prehispánicas del norte chileno, siendo después retomada por Oyarzún, Latcham y Le Paige para nombrar a los habitantes prehispánicos del oasis, de la misma manera que fue utilizada por L. Núñez, Bittmann y Llagostera, y, más recientemente, por Uribe, Adán, Agüero, Cases y Ayala, entre otros, para designar a poblaciones prehispánicas tardías del Salar y de la cuenca del Loa. Al parecer, el concepto de atacameños se popularizó por diferentes medios (textos de difusión e investigación, textos escolares y salas de exhibición), siendo inicialmente adoptado por la población local para designar a los habitantes del oasis y desde los años 90 para su reconocimiento ante el Estado. Es así como se adopta el concepto de atacameños para denominar a la población del Salar de Atacama y de la cuenca del Loa, que históricamente se caracterizó por su heterogeneidad, tratándose de un nombre más bien neutral que actualmente funciona en términos étnicos.

Por su parte, el Estado se constituye en un promotor eficaz y sistemático del discurso étnico en Chile, lo cual se desarrolla a partir de una política estatal multiculturalista implementada desde la promulgación de la Ley Indígena. El rol del Estado en la construcción de los discursos étnicos también se observa en la importancia alcanzada por la noción de patrimonio en dichos discursos, en los cuales se promueve un concepto de identidad étnica asociada a un patrimonio cultural que es necesario proteger, poner en valor y manejar. Paralelamente a esto, el Estado difunde un discurso de continuidad histórica en la Ley Indígena al sostener que estas poblaciones son descendientes de las sociedades prehispánicas, lo cual evidencia una concordancia entre el discurso estatal y el construido por la arqueología.

En los últimos años el discurso patrimonial del Estado ha sido apropiado y resignificado de manera diferencial por distintas etnias del país, en circunstancias que entre los atacameños este discurso ya estaba instalado con anterioridad al proceso de emergencia étnica. En este período se diversifican los significados otorgados al patrimonio arqueológico en Atacama. En efecto, por un lado, se le identifica un valor identitario ya que se constituye en un repertorio cultural que permite establecer fronteras grupales y delimitar lo propiamente atacameño. Por otro lado, el patrimonio arqueológico tiene un valor territorial ya que la administración de sitios es utilizada para demostrar la "ocupación real" de su territorio, tal como lo solicita el Ministerio de Bienes Nacionales (en adelante MBN). Además, dichos bienes tienen una valoración económica que les permite insertarse en el mercado cultural, generar fuentes de trabajo y mejorar su situación monetaria, a lo cual se suma el valor político que se les otorga al ser utilizados para acumular poder y acceder a espacios más amplios de influencia y control de recursos. De este modo, desde una situación de marginalidad en relación al patrimonio cultural, actualmente los atacameños asumen una postura de empoderamiento sobre el mismo, en la cual este patrimonio tiene tanto un valor simbólico como económico, es reivindicado como parte de su identidad y a la vez que como mercancía.

En estas circunstancias, el discurso de continuidad histórica y la identificación con los vestigios arqueológicos como obras y restos humanos de sus antepasados se constituye en un argumento de diferenciación histórica y cultural. Junto con esto, la "tradición atacameña" se nutre, entre otros recursos, de los discursos patrimonial y arqueológico, ya que en la actualidad existe un proceso de recuperación de las tradiciones perdidas, a través de proyectos de rescate de la memoria oral y de la lengua kunza, de reactivación de ceremonias desaparecidas y de prácticas precolombinas. De este modo, la etnia atacameña es una identidad que mira hacia el pasado, un pasado glorioso de resistencia cultural cuyos vestigios materiales aportan en la construcción de una imagen e historia de sí mismos, pero también se trata de una identidad articulada y resultante de los procesos de modernización vivenciados a nivel regional y nacional. A ello hay que sumar su integración en el proceso de globalización creciente, a partir del cual algunos de sus dirigentes se conectan con otras agrupaciones indígenas de América y acceden a información y experiencias a nivel internacional.

En este escenario de reivindicación étnica, el valor otorgado al respeto y temor a los "abuelos", exis- 
tente desde momentos previos a la instalación de la práctica arqueológica en la zona, se resalta como lo "tradicionalmente atacameño", como "lo propio", lo cual actualmente se asocia al discurso de los antepasados, ya que los "abuelos" o "gentiles" pasaron de ser entidades de otra humanidad a identificarse como antepasados de los atacameños. Esto, sin duda, les permite diferenciarse de la sociedad mayor, en circunstancias que la noción de "abuelos" es ambigua, ya que puede aludir tanto a los antecesores de un grupo humano como a gente antigua cuyos restos materiales se encuentran distribuidos en el territorio ocupado por una población, razón por la cual es útil como herramienta identitaria y política. También es necesario distinguir entre la noción de antepasado como ascendiente, progenitor y pariente, de aquella referida a gente del pasado con la cual no se tiene un vínculo familiar pero que se asume que forman parte de la historia de una población. Recordemos que la invención de la tradición no puede basarse en elementos escogidos al azar ya que para que dicha invención se enraíce debe incluir características reconocibles por el grupo y la sociedad en general, que le den un aura de historicidad (Koonings y Silva 1999). En el caso atacameño esto parece lograrse, entre otros recursos, a través de un discurso basado en los ancestros y en la continuidad histórica, así como en afirmaciones referidas a su proceso de aprendizaje con los "abuelos" y la exaltación de la memoria local.

Al mismo tiempo se desarrolla un juego de representaciones sociales en el cual ciertos dirigentes atacameños utilizan reproducciones de vestimentas y tocados precolombinos, así como otros replican prácticas prehispánicas como la producción de herramientas líticas por considerarlas como parte de su acervo cultural. Esto responde a la demanda de autenticidad que impone la sociedad en general, ya que en este proceso de reivindicación étnica no basta con identificarse como indígena o como miembro de un grupo étnico sino que es necesario autorrepresentarse como tal. Esto debido a que nuestra sociedad define, valora y legitima aquello que es considerado "auténticamente indígena", lo cual sin duda se vincula a una imagen estereotipada y a una concepción nostálgica de los indígenas, a quienes se define desde la exoticidad, ya que se los quiere ver "vestidos de indios" porque su auténtica presencia, "sin poncho y con celular en mano", no les basta para ser reconocidos como tales. En estas circunstancias, es común ver algunos dirigentes que se autorrepresentan como indígenas a través de "rituales de autenticidad" (sensu Benavides 2004), con vestuarios y símbolos que reafirman su ser indígena y con nombres en idiomas que ni siquiera hablan. En este contexto, la recuperación o validación de símbolos y prácticas consideradas como tradicionales no sólo nutren un proceso de "invención de tradición", sino también la creación y reproducción de "ritos de autenticidad" con los cuales algunos dirigentes atacameños satisfacen la necesidad de autenticidad u originalidad que la sociedad, el Estado chileno, los organismos internacionales y el mercado les demandan.

Este proceso de diferenciación colectiva de la década de los 90 impulsó la instalación de conceptos inexistentes anteriormente en Atacama: "el 76...nadie hablaba de afuerino, nadie hablaba de eso. Yo me acuerdo que cuando venía la gente de afuera se sentaba en la mejor mesa, compartía con nosotros, era bienvenido" (Atacameño 3, 2004). Asimismo, los años inmediatamente anteriores y posteriores a la promulgación de la Ley Indígena se describen como etapas conflictivas en San Pedro de Atacama, en las cuales los discursos se radicalizan y se genera una serie de problemas entre la población local y los "afuerinos", entre miembros de las comunidades, y entre éstos y los arqueólogos.

A esto se añade que en estos años el turismo se constituye en una de las actividades más importantes de San Pedro de Atacama, lo cual genera problemas entre atacameños y "afuerinos", quienes no sólo tienen las mayores inversiones económicas en este rubro sino también un amplio manejo y preparación en este tipo de negocios, a diferencia de los atacameños. Se suma que el turismo desarrollado en esta localidad y sus alrededores no sólo promueve la belleza paisajística de la zona sino las particularidades culturales de sus habitantes, los que son descritos en folletos y páginas web de empresas turísticas como los descendientes de una cultura milenaria. Además, este poblado es catalogado como "la capital arqueológica de Chile" y su museo se considera como uno de los atractivos turísticos más visitados de la zona. En estas circunstancias, algunos atacameños plantean que "otra invasión" es la de los turistas, lo cual se vincula con la percepción de que sus comunidades no se benefician, como quisieran, de una actividad que se sustenta en su patrimonio, lo cual también se hace extensivo a la arqueología.

Al mismo tiempo, al interior del aparato estatal se genera una serie de discusiones sobre la propiedad del 
patrimonio indígena. En efecto, poco tiempo después de iniciadas las labores de la CONADI local, "la apuesta" de esta institución fue transferir a nombre de las comunidades atacameñas determinados sitios arqueológicos, sin embargo, en pleno proceso de regularización y de presentación de los expedientes al MBN, hubo desacuerdos con la CONADI central. A pesar de esto, teniendo en cuenta que la demanda de las comunidades atacameñas era la transferencia de los sitios arqueológicos, la CONADI local "da la pelea", apostando a que las comunidades pueden hacerse cargo de este proceso y considerando que la Ley Indígena los apoya en este sentido. Se relata que la CONADI local tuvo grandes discusiones con el MBN y el CMN por la transferencia de los sitios, ya que estos servicios públicos planteaban que estos bienes eran de propiedad estatal, mientras la CONADI local defendía la postura de que era un patrimonio de las comunidades indígenas. Finalmente, los sitios arqueológicos no se transfirieron a los atacameños sino que fueron entregados a ellos por el MBN, para su administración comunitaria.

Dentro de las políticas estatales orientadas al trabajo con el patrimonio cultural y al desarrollo de alternativas laborales para las poblaciones indígenas, a mediados de los 90 la CONADI local inicia el proceso de puesta en valor, protección y manejo de sitios arqueológicos para su aprovechamiento turístico. El primer proyecto de este tipo fue el de la aldea de Tulor, la cual fue solicitada por la comunidad atacameña de Coyo para su administración. Inicialmente hubo posiciones encontradas en cuanto al tipo de proyecto a realizar en este sitio, entre representantes del Museo de San Pedro de Atacama, arqueólogos externos a esta institución, atacameños, la CONADI y el CMN, planteándose incluso la existencia de alianzas entre la CONADI local y las comunidades, por un lado, y, por otro, el Museo y el CMN. Asimismo, se describen posturas contrarias a este proyecto de parte de algunos atacameños, quienes proponían tapar este sitio y no permitir su uso turístico.

Según miembros de la comunidad de Coyo en los inicios de este proceso los atacameños no contaron con el apoyo del museo local y el CMN, ya que estas instituciones consideraban que no estaban capacitados para administrar el sitio. Si bien tenían el apoyo de la CONADI y la Municipalidad de San Pedro, necesitaban trabajar con un arqueólogo, pero ni ellos ni profesionales del Museo se acercaron para abordar este proyecto en conjunto. En estas circunstancias, trabajaron con un equipo de arqueólogos externos a esa institución, que contaba con un proyecto de puesta en valor para la aldea de Tulor, aunque según la profesional a cargo: "ahora la comunidad aparece como que fueron ellos, incluso creen ellos, que lo hicieron ellos solos" (Arqueólogo 2, 2004). De acuerdo a los atacameños, existía una barrera entre los arqueólogos del Museo y la comunidad, la cual se interpreta como "temor o desconfianza de si realmente éramos capaces de hacerlo" (Atacameño 8,2004 ), aunque también algunos plantean que estos problemas se relacionaron con la participación en este proyecto de arqueólogos externos a esa institución. Se afirma, además, que parte de las aprensiones de los arqueólogos del Museo y del CMN se relaciona con la posibilidad de perder autoridad sobre los sitios arqueológicos al ser administrados por los atacameños.

Al respecto, es evidente una visión negativa de los arqueólogos por parte de los atacameños, la cual se explica por el cuestionamiento que estos profesionales hicieron de sus capacidades. Sin embargo, no se reconoce la existencia de intereses y valores diferentes entre ellos, así como tampoco se asume la necesidad de manejar ciertos conocimientos técnico-profesionales para llevar a acabo este proceso, lo cual efectivamente ha derivado en problemas de protección y deterioro del patrimonio arqueológico. De este modo, quizá como un reflejo de su relación con la sociedad mayor, entre los atacameños se activa la percepción de ser discriminados por ser indígenas, de ser "mirados desde arriba", de ser "pasados a llevar" por los arqueólogos. Es así que comienzan a polarizarse las posiciones entre los actores de este proceso, identificándose los que están a favor de los indígenas y los que están en contra de sus intereses. Estas posiciones, más que criterios diferentes, se perciben como la negación de las motivaciones del otro. En este contexto, mientras los indígenas consideran relevante construir infraestructura adecuada para la administración de los sitios arqueológicos, los arqueólogos se preocupan fundamentalmente por su protección e investigación. A esto se suman perspectivas de trabajo diferentes y conflictos al interior de la arqueología, ya que en una época en la cual la puesta en valor y el manejo de los sitios arqueológicos no era una labor activa en la arqueología nacional, esta práctica fue vista críticamente por algunos profesionales, aunque ciertamente no desde una posición radicalmente contraria, pero tampoco desde una que aportara alternativas en las cuales confluyeran los intereses involucrados. 
En este período las demandas y críticas de los atacameños respecto a la práctica arqueológica y al Museo son públicas, en circunstancias que los indígenas cuentan con un sustento legal y un ambiente favorable para reivindicar sus derechos respecto al patrimonio arqueológico. Ya no se trata de conversaciones entre pasillos, en las cuales se critica a los arqueólogos o se dice no estar de acuerdo con sus excavaciones, sino de demandas planteadas en reuniones y seminarios y a través de acciones realizadas por organizaciones indígenas. De este modo, en un contexto de polarización de los discursos, se activan relaciones de negación entre los actores involucrados, los cuales, además de negarse entre sí, no establecen vínculos y desconocen o ignoran los intereses y necesidades del otro. De parte de los arqueólogos se observa una desvinculación del proceso étnico que se desarrollaba en San Pedro de Atacama, además de un desconocimiento de las demandas, intereses y valoraciones indígenas relacionadas con la práctica arqueológica. Por otro lado, los dirigentes étnicos estereotipan a los arqueólogos como saqueadores de tumbas y como profesionales que "ganan" con su cultura, además de negar o ignorar los cambios en el desarrollo de la arqueología, desconocer sus intereses científicos y prohibir el acceso de los arqueólogos a determinados sitios.

En el Primer Congreso Atacameño (1998) se manifiestan diferentes críticas a la arqueología desarrollada en la zona, se la señala como causante de la destrucción del patrimonio cultural atacameño, poniéndola al mismo nivel del impacto ambiental generado por los proyectos mineros. Junto con esto, por alrededor de cuatro años consecutivos, los días 12 de octubre se realizan "velatones" frente al Museo Arqueológico de San Pedro de Atacama, lo que si bien surgió espontáneamente en un principio, posteriormente se replica por personas y organizaciones indígenas que consideran que en el Museo están sus antepasados, los cuales para ellos representan lo más puramente atacameño, a diferencia de las festividades relacionadas con la religión cristiana, también suyas, pero traídas de afuera. Esto evidencia discursos de diferenciación y dicotomía entre lo indígena y lo no indígena, lo cual se vincula con posturas más bien radicales de parte de algunas agrupaciones indígenas que buscan reactivar una religiosidad ancestral, dejando de lado lo impuesto por la cultura dominante.

Mientras se desarrollan estas manifestaciones por parte de los atacameños, los profesionales del Museo consideran que "estábamos muy distanciados, nos habíamos dedicado al trabajo académico científico, estábamos encerrados en una burbuja dentro del propio corazón de la etnia atacameña, lo cual no puede ser bueno" (Arqueólogo 7, 2004). Asimismo, se plantea que el problema de la inexistencia de relaciones con la comunidad indígena radica en que "el Instituto no siguió el proceso étnico, se desentendió de lo que pasaba fuera de él, se marginó, entonces se comenzó a generar una brecha, a gestar un rechazo para con el Museo" (Arqueólogo 7, 2004). Este distanciamiento evidencia una negación de las demandas indígenas de parte de los arqueólogos y el Museo, ya que se conocía la existencia de demandas y críticas a la disciplina y a la institución, así como la realización de actividades contrarias a ellas, sin embargo, se desconoce este proceso o se desentienden de él. En este sentido, se relata que los velatorios organizados frente al Museo fueron tomados con "indiferencia", como si fueran acciones naturales del 12 de octubre que nunca se asumieron como problema institucional. Para otro profesional de esta institución estos actos fueron intrascendentes:

"una vez un grupo de jóvenes de San Pedro, sin discurso, pusieron velas en ciertas partes dentro del Museo y afuera en toda la puerta. Pero fuera de esos velatorios y de algunos gritos y algunas cosas así, con algunas pancartas frente al Museo, de un acto de unos 15 minutos, no tuvo ninguna trascendencia, no lograron impactar" (Arqueólogo $8,2004)$.

Estos actos no involucraron a toda la población, sino más bien a agrupaciones atacameñas cuya postura es definida como "radical" por atacameños, arqueólogos e instituciones involucradas, sin embargo, se trata de manifestaciones de un sector de la población indígena que pudieron ser consideradas por esta institución. Llama la atención que los dirigentes étnicos de la época, adscritos o no a posturas de este tipo, recuerdan estas actividades como manifestaciones relacionadas con sus derechos y con la solicitud de respeto por sus antepasados. Asimismo, atacameños pertenecientes a la agrupación Zhali Lickan Ckappur de Calama relatan que en una ocasión "se tomaron el Museo", mientras profesionales de esta institución desconocen o ignoran esta situación: "toma, toma, no hubo toma", evidenciándose así no sólo su distanciamiento de la comunidad local sino también que no comprendían los códigos de estas manifestaciones atacameñas. Este hecho es corroborado por un funcionario del Museo: 
"El 2002 me parece, el 2001, porque fue la última protesta que hicieron. Llegaron al Museo alrededor de las 4 de la tarde y entraron. Tiraron, bueno, una llijlla en el piso, pusieron coca.... [empezaron] hacer como un pago ahí. No se le entendía realmente qué es lo que es porque no tenía aloja, no tenía coca, no tenía alcohol que era lo otro que consumía la gente antigua...nada, chicha por último de maíz, nada. Entonces hacer un pago con lo que ellos nunca consumieron es como raro. Además en el flexit no le iban a poder echarle a la Pacha, nada. Entonces estuvieron ahí hablando unas palabras y después salieron hacia afuera y ahí nuevamente empezaron a hacer un pago a la entrada, a la mano derecha, ahí se arrodillaron y ahí estaban dando la bronca" (Atacameño 6, 2004).

El año 2000, en vísperas del 12 de octubre, se intentó quemar el Museo. Hasta el momento, no se ha atribuido legalmente la autoría de este hecho a personas o agrupaciones específicas, aunque se cuenta con interpretaciones acerca del contexto en que se desarrolló este y otros hechos de la época (Gundermann $2002 \mathrm{Ms}$ ). ${ }^{8}$ Para los arqueólogos del Museo se trata sin duda de una manifestación de la comunidad atacameña, y para algunos de ellos es "el punto cúlmine de la ruptura del Instituto, la academia y la comunidad indígena" (Arqueólogo 7, 2004). Esta situación no se tomó como un problema institucional vinculado con las relaciones establecidas con la comunidad, sino más bien como un peligro para el Museo y para ellos:

"no se tomó ninguna decisión de fondo. Porque para mí la situación de fondo era no solamente reconocer la necesidad que había que ser más actuantes con la comunidad, de no ser algo tan ajeno a ellos, sino que de hacer algo" (Arqueólogo 6, 2004).

Por otro lado, este acto fue repudiado públicamente por los propios atacameños, para los cuales se trata de algo "imperdonable" ya que pudieron quemarse sus antepasados y destruirse su patrimonio.

Una situación que es considerada como otro hito del distanciamiento entre arqueólogos y atacameños es la construcción del hotel Explora en San Pedro de Atacama. Se relata que para autorizar su construc-

8 Cabe mencionar que un año después fueron quemados los principales santos de la iglesia de San Pedro de Atacama, así como un año antes se intentó quemar la oficina de CONADI en Calama (Gundermann $2002 \mathrm{Ms}$ ). ción se realizó un informe arqueológico que estuvo a cargo de profesionales externos al Museo. Una vez logrados los permisos correspondientes, incluyendo el del CMN, los atacameños comenzaron a protestar y decir que los arqueólogos del Museo elaboraron el mencionado informe. Contrariamente a esto, funcionarios de esta institución plantean que la participación del Museo se limitó a supervisar las excavaciones una vez otorgados los permisos correspondientes. Según otros actores, la mala información y la confusión de parte de los atacameños conllevó a que se tildara a los arqueólogos del Museo de "vendidos", acusarlos de ocultar la existencia de sitios arqueológicos y de hacer informes favorables a la empresa hotelera. En este sentido, el cuestionamiento indígena a la instalación de este hotel consideraba que esta empresa beneficiaría a la gente de afuera y no a los atacameños, además de plantearse que la compra de terrenos para su construcción se hizo a base de "mentiras" y reclamar que su construcción destruiría un cementerio. Finalmente el hotel fue edificado y las manifestaciones atacameñas contrarias a ello, acalladas.

Como se puede apreciar, los años posteriores a la promulgación de la Ley Indígena fueron conflictivos en San Pedro de Atacama, lo cual se vincula con fluctuaciones en la forma de interactuar de los actores, ya que de relaciones de colaboración para el reconocimiento de la etnia atacameña, se produce un giro de parte de los arqueólogos hacia el desconocimiento o ignorancia de los procesos, demandas e intereses indígenas. Paralelamente a esto, algunos dirigentes y agrupaciones atacameñas radicalizan sus posturas respecto a la arqueología y al museo local, a lo cual se suman las aprensiones manifestadas por dirigentes con perspectivas más abiertas al diálogo, aunque no por ello menos críticas.

Algunos arqueólogos consideran que no estaban preparados para enfrentar el proceso de emergencia étnica, que "no tenemos problemas frente a lo que debemos hacer y no hacer frente a la arqueología, pero sí tenemos problemas frente a las sociedades vivas" (Arqueólogo 8, 2004). Además, se plantea que la antropología se integró al Museo de San Pedro de Atacama pensando que "fuera el nexo con la comunidad y nunca lo fue" (Arqueólogo 7, 2004), y se señala que esta institución no contaba con recursos para abordar la "ruptura" con la comunidad atacameña. Al respecto, llama la atención la percepción de la arqueología como una disciplina disociada de su entorno social, una profesión con dificultades de interactuar con las sociedades contemporáneas, a 
pesar de que históricamente los arqueólogos hayan establecido relaciones de diferente tipo con los atacameños. Se trata de una visión esencialista de la arqueología y la antropología, en la cual cada una tiene un campo de interés muy focalizado, percibiéndose su desarrollo como algo paralelo más que complementario.

En cuanto a la antropología, en este período se produce una institucionalización del aporte de esta disciplina dentro del aparato público y de las universidades en el norte de Chile (Gundermann y González 2005 Ms). En este contexto, ingresan antropólogos a unidades históricamente dedicadas a la arqueología, como el Museo de San Pedro de Atacama, generando un aporte académico a partir del cual se comienzan a publicar, por ejemplo, estudios referidos al problema étnico en Atacama (Rivera 1997 en adelante; Gundermann 1997 en adelante). Paralelamente se efectúan estudios etnográficos en otras localidades del Salar de Atacama al alero de universidades de Santiago (p.e. Morales 1997; M. Núñez 2002). Sin embargo, los problemas de investigación y la orientación teórico-metodológica de los estudios desarrollados en estas localidades y en el oasis de San Pedro de Atacama no consideraban una línea de trabajo complementaria entre la arqueología y la antropología, lo cual parece incidir en la percepción de algunos arqueólogos de que la antropología no acompaña el proceso de emergencia étnica relatado en estas páginas.

A diferencia de lo anterior, en la cuenca superior del río Loa las investigaciones arqueológicas integraron estudios etnográficos y etnoarqueológicos, continuando así con la línea de trabajo iniciada anteriormente en Toconce (Varela 1992; Adán 1996; Uribe 1996; Mercado et al. 1997; Villaseca 2000, entre otros). En general, desarrollan actividades de difusión hacia la comunidad local, además de realizar reuniones informativas con sus directivas y abocarse, fundamentalmente, al estudio de colecciones y de sitios habitacionales. En estos casos, la complementación de la arqueología y la etnografía ayudó al establecimiento de relaciones cercanas y de participación de los arqueólogos en ciertas actividades de las comunidades indígenas, destacando aproximaciones novedosas a nivel nacional en términos de la inclusión de la perspectiva indígena en las investigaciones arqueológicas. Este es el caso, por ejemplo, de la integración de las interpretaciones indígenas del arte rupestre en los estudios arqueológicos del río Salado (Castro y
Gallardo 1995-1996), así como la etnografía realizada sobre la etología de camélidos con el fin de interpretar dichas manifestaciones rupestres (González 2002), además de las investigaciones referidas a la memoria oral relacionada con la presencia incaica (Aldunate et al. 2003).

Esto sucede en circunstancias que la Ley Indígena se promulga en 1993, siendo recién cuatro años después que comienzan las repercusiones del proceso de emergencia étnica en la arqueología del Loa Superior, a pesar del tipo de relaciones de cercanía establecidas entre arqueólogos e indígenas en esta zona. Esto se vincula con posturas radicalizadas sobre todo de parte de dirigentes jóvenes que plantean críticas y demandas públicas a la disciplina, a diferencia de lo ocurrido con los líderes más antiguos cuyas posiciones, en general, son más abiertas al diálogo (Miranda 1997). De este modo, a finales de los 90 se producen situaciones puntuales en las cuales, por ejemplo, se interpela a un equipo de investigación sobre su autorización para trabajar en Caspana. Junto con esto, se impulsan aprensiones y críticas de los atacameños respecto a los beneficios económicos obtenidos por los libros escritos sobre "su cultura", teniendo los profesionales involucrados que realizar aclaraciones ante dirigentes de las comunidades correspondientes. A este contexto de polarización de los discursos indígenas del Loa Superior, se suman dirigentes de Lasana y Chiu Chiu cuyos planteamientos se asemejan a los escuchados en San Pedro de Atacama. De este modo, tanto líderes étnicos como agrupaciones del Salar y cuenca del Loa establecen relaciones de negación con los arqueólogos, desconociendo los aportes de esta disciplina, los diferentes tipos de interacción mantenida a lo largo del tiempo, así como sus intereses y valores científicos. Un ejemplo de ello es negar la autorización para realizar excavaciones arqueológicas en el territorio de algunas comunidades atacameñas, como la de Río Grande, a pesar de la solicitud de permiso comunitario de parte de los profesionales involucrados.

Se relatan, además, conflictos por el ingreso a sitios administrados por los atacameños, siendo un ejemplo de ello el episodio vivenciado por una arqueóloga en San Pedro de Atacama. De acuerdo a esta profesional, prácticamente fue "sacada a patadas" por un dirigente que reclamaba que los arqueólogos piensan que pueden hacer lo que quieren; según sus palabras, "mira, me ofendió de todas las formas, como arqueóloga, como persona" 
(Arqueólogo 6, 2004). Ante situaciones de este tipo, otros profesionales dicen que "no podemos dejar que los atacameños nos suban y nos bajen, hay un respeto que tiene que tenerse en cuenta" (Arqueólogo 7, 2004). Otros arqueólogos afirman que anteriormente no tenían problemas para ingresar a los sitios pero que ahora incluso están cercados, lo cual es visto como "un acto violento y de negación de algo que es de todos" (Arqueólogo 9, 2004) y que se relaciona principalmente con que "no das plata". Asimismo, otros arqueólogos manifiestan que no pedirán autorización a las comunidades indígenas, ya que no corresponde y basta con la autorización del CMN.

Por otro lado, en diferentes instancias los atacameños plantean una serie de demandas a la arqueología, las cuales se refieren a no exhibir y excavar cuerpos humanos, la propiedad y administración del patrimonio arqueológico, la solicitud de información sobre las investigaciones arqueológicas, de permiso comunitario para trabajar y de participación indígena en el quehacer disciplinario, además de la demanda de administrar el Museo Arqueológico de San Pedro de Atacama. Asimismo, afirman que tienen que contar con sus propios arqueólogos y antropólogos para que así estos profesionales dejen de "usufructuar de su cultura", siendo recurrente escuchar en algunas reuniones la importancia de contratar a profesionales indígenas y no a "afuerinos" o "santiaguinos". De este modo, en determinadas situaciones, como en los proyectos de impacto ambiental, se dice que entre creerle a una persona de la comunidad sobre la presencia de un sitio arqueológico y creerle a un arqueólogo, es necesario validar el conocimiento de "nuestra gente", acusando a los arqueólogos de estar al lado de los intereses privados, enriquecerse y no considerar su opinión.

Estas relaciones de negación mutua han producido conflictos basados en posturas esencialistas, prejuicios e incluso en la descalificación entre sí de los actores de este proceso. De este modo, algunos atacameños plantean que los arqueólogos "engañan" a los indígenas, que son "huaqueros con título", que se trata de gente que "usufructa", "se enriquece" y "lucra" con su cultura, que "no se preocupan por las necesidades del pueblo", que se "apropian", "venden" y "roban" su patrimonio, que "prometen y no cumplen", que se "aprovechan de ellos", que son "usurpadores de su cultura", "depredadores de su cultura", que "hacen lo que quieren en los sitios", que "no nos respetan", es gente de la cual desconfían y, en el caso de Le
Paige, temían. Por otro lado, algunos arqueólogos plantean que a los atacameños "sólo les interesa la plata" que obtienen de los sitios, que "tienen el signo pesos en sus ojos", que "son fundamentalistas", que "venden su patrimonio", que "no tienen discurso", que "sólo buscan provecho político", que tienen que "ubicarse", que son "resentidos y desconfiados con los arqueólogos", que "nos odian y ven como opresores."

En este contexto, por un lado se plantea que las comunidades indígenas son fundamentalistas y atentan contra el conocimiento científico y, por otro, se caracteriza a los arqueólogos como verdaderos enemigos de los intereses indígenas, en circunstancias que cada actor defiende sus propios intereses y valoraciones. De este modo, el hallazgo de entierros en investigaciones arqueológicas o en estudios de impacto ambiental ha llevado a algunos arqueólogos a invisibilizar al otro, es decir, reservarse este tipo de información con el fin de no tener problemas; en otros casos se han realizado estudios arqueológicos prácticamente a escondidas de la comunidad atacameña. Además, si bien se dejó de excavar cementerios hace algunos años, aún pesa el estereotipo del arqueólogo excavador de tumbas heredado desde las expediciones científicas en el Loa y tiempos de Le Paige, por lo que los atacameños continúan usando este argumento como crítica a la disciplina, negando o ignorando así los cambios producidos en la historia de la arqueología. Paralelamente, algunos arqueólogos reproducen el estereotipo de los indígenas como miembros de sociedades sin historia, planteando que la arqueología es una disciplina que viene a llenar este vacío, desconociendo así las construcciones indígenas del pasado.

El esencialismo de estas posiciones permite que así como se reivindica la validez del discurso indígena del pasado no se acepta que la producción arqueológica sea igualmente significativa (Gnecco 2004). Esta situación también ha producido polarizaciones al interior de la disciplina, ya que para ciertos investigadores la caracterización de los indígenas como anticiencia refuerza el estereotipo del indígena no progresista (Bray 2001), para otros el estereotipo del arqueólogo como buscador de tesoros y saqueador de tumbas niega el desarrollo disciplinario. En este proceso los arqueólogos no asumen la historia de la disciplina y las consecuencias generadas por las relaciones de negación, replicando esta forma de interactuar en la actualidad al ver que sus intereses profesionales son cuestionados por los indígenas. Por 
otro lado, al vincularse con los arqueólogos desde la negación, los atacameños cambian una exclusión por otra y replican el mismo tipo de relación que los ha llevado a criticar a los arqueólogos y plantear demandas a la disciplina. Además, considerar a la arqueología como enemiga de los intereses indígenas, es desconocer el aporte que ha efectuado y puede realizar esta disciplina en el proceso de reivindicación étnica, el desarrollo de proyectos turísticos, de manejo de sitios y colecciones arqueológicas, así como en la implementación de museos comunitarios y la evaluación de proyectos de impacto ambiental, entre otros.

Pese a lo anterior, también se identifican perspectivas diferentes, ya que se distinguen dirigentes atacameños dispuestos a dialogar. En este sentido, no se puede plantear que este período se caracteriza solamente por posiciones y un contexto netamente polarizado, sino más bien por la existencia de posturas radicalizadas y etapas en las cuales priman discursos esencialistas y relaciones de negación. En los últimos años, a pesar de que aún se identifican discursos radicalizados, también se desarrollan relaciones de diálogo, negociación y colaboración entre los actores de este proceso, lo cual es reconocido por miembros de la comunidad atacameña: "encuentro que es súper bueno que el Museo esté abriendo sus puertas a las comunidades, ya que nosotros también, desde el punto de vista como atacameños y de manera independiente al cargo que tengamos, fuimos viendo como algo súper lejano el Museo" (Tercera Mesa de Diálogo, 2005).

La apertura al diálogo y la negociación ha partido tanto de los atacameños como de los arqueólogos y los funcionarios estatales. Respecto a las iniciativas realizadas por los atacameños, éstos manifiestan que no pueden estar ajenos a relacionarse con los arqueólogos porque:

"la arqueología se sigue desarrollando por acá, por un lado. Y, por otro lado, está también el interés de alguna gente de conocer el trabajo, participar de ese trabajo arqueológico por una parte, y lo otro tiene que ver con el pueblo" (Atacameño 1, 2004).

Para esto ha sido necesario crear un espacio de diálogo y negociación, que se ha concretado en la realización de encuentros de discusión organizados por agrupaciones indígenas, en colaboración con la CONADI, como los desarrollados en Cupo (2000), Lasana (2003) y Caspana (2005). Estas reuniones, conocidas como "Diálogos en la Puna", han sido convocadas por la Asociación Cultural Indígena Atacameña de Tradiciones y Costumbres de la Comuna de Calama, en coordinación con la directiva de estas comunidades. En general, las reuniones tienen un carácter informativo, y es en ellas que algunos arqueólogos presentan resúmenes de sus investigaciones, así como los atacameños dan a conocer sus iniciativas, críticas e inquietudes respecto al quehacer arqueológico.

En el caso de los arqueólogos, este proceso de apertura al diálogo y la negociación no sólo se vincula con una forma de dar respuesta a las demandas sociales planteadas a la disciplina, sino también con las repercusiones disciplinarias causadas por este proceso (Navarro 1998; Chungara, Revista de Antropología Chilena 35 [2], 2003). Es así que se han iniciado discusiones acerca de las consecuencias sociales de la práctica arqueológica y la influencia del contexto histórico en la construcción de conocimiento, además de abrirse una línea de trabajo vinculada específicamente con el desarrollo de proyectos patrimoniales. El año 2001 se ejecutó un proyecto orientado a realizar una serie de acciones con miras a subsanar el distanciamiento existente entre arqueólogos y comunidades indígenas (Ayala et al. 2003). Uno de sus resultados fue la realización de un encuentro de reflexión en Ollagüe, en el cual, de manera similar a lo ocurrido en experiencias anteriores organizadas por arqueólogos en Ayquina y Caspana, se reunió a dirigentes de comunidades indígenas, arqueólogos y antropólogos, además de representantes de las instituciones y organismos vinculados a este tema.

En este mismo año en el Museo Arqueológico de San Pedro de Atacama se inician acciones dirigidas a mejorar las relaciones con la comunidad atacameña, lo cual se produjo sólo una vez alcanzado el peak de los problemas con la población local, el cual es asociado al intento de quemar el Museo. De acuerdo a profesionales de esta institución, la primera actividad fue la realización de una Mesa de Diálogo:

"vinieron los dirigentes prácticamente sin un temario, sino el tema central era ese, relaciones, la necesidad por parte nuestra de estructurar una buena relación con las comunidades. Entonces, la pregunta a las comunidades era, ¿qué esperaban ellos del Instituto y cómo veían que el Instituto podía insertarse con la comunidad y ofrecer entonces abrir las puertas hacia la comunidad? Fue un diálogo bastante 
fuerte digamos, pero interesante, importante, las comunidades nos dijeron, nos dieron la lista de las cosas por las cuales pensaban que nosotros no estábamos comprometidos con ellos, fue muy bueno en el sentido de que yo diría que fue una verdadera catarsis y a partir de este momento ya se relajó un poco la tensión digamos entre el Instituto y la comunidad y ahí se plantearon algunas actividades, bueno, algunas se venían proponiendo desde antes, como por ejemplo la Escuela Andina, pero se le dio prioridad para desarrollarla a partir de ese momento, fue así que en ese momento se echa andar la Escuela Andina y se comienza entonces a buscar formas de trabajar con las comunidades" (Arqueólogo 7, 2004).

Los arqueólogos que participaron de esta reunión afirman que los temas planteados por los atacameños fueron: la exhibición de cuerpos en el Museo, las excavaciones arqueológicas, la indiferencia profesional e institucional hacia sus necesidades, y los recursos humanos y económicos que no se ponían a su disposición. El año 2005 se realizó la Tercera Mesa de Diálogo para conocer las percepciones, intereses y sensibilidades de la población atacameña, ya que esta institución museal se encuentra en un proceso de formulación de una política de vinculación con la comunidad indígena. Una de las repercusiones de este proceso ha sido la valoración positiva de la arqueología de parte de algunos atacameños, lo cual queda reflejado en su solicitud de participar activamente de las labores arqueológicas. Junto con esto, es evidente el interés de los atacameños de apropiarse e involucrarse, mediante diferentes vías, del quehacer del Museo, en el sentido de que éste es pensado y sentido como un espacio que depende en última instancia de su patrimonio. En este contexto, en esta reunión se presentaron propuestas y solicitudes de mayor participación e inclusión de los atacameños en las actividades institucionales, sobre todo en investigación y en el programa de educación patrimonial denominado Escuela Andina, así como en la toma de decisiones que comprometan su patrimonio.

Entre los arqueólogos entrevistados hay consenso respecto de la importancia del diálogo para mejorar las relaciones con las comunidades indígenas, así como el generar relaciones de confianza, colaboración y trabajo en conjunto. También se plantea que el diálogo, el establecimiento de relaciones más cercanas y la realización de actividades de difusión han generado un cambio en la forma de relacionarse y en el modo de pensar de algunos dirigentes, antes contrarios a la arqueología y al Museo de San Pedro de Atacama. Se manifiesta, además, la importancia de generar un diálogo con la comunidad en general, estableciendo relaciones con las bases y no sólo con los dirigentes, lo cual se vincula con una percepción negativa de estos últimos, ya que en algunas ocasiones su perspectiva hacia la arqueología suele ser más cerrada o radical que la de otros miembros de la comunidad.

Al mismo tiempo, se identifican relaciones de colaboración entre los actores de este proceso, las cuales apuntan a contribuir con conocimientos y prácticas a la consecución de un objetivo o proyecto relevante para los mismos. Uno de los campos más fructíferos de colaboración ha sido la ejecución del programa de educación patrimonial denominado Escuela Andina ${ }^{9}$, además de la realización de asesorías profesionales en el ámbito de la investigación y la museología. Esto se ha realizado ahora que los atacameños asumen la falta de capacidades técnicas en sus comunidades: "necesitamos asesorías técnicas, como apoyo técnico, como asistencia técnica: abogados, antropólogos, arqueólogos, pero positivos, no negativos, con altura de miras, no que especulen" (Atacameño 8, 2004). De este modo, el museo local ha respondido a demandas formuladas por los líderes étnicos sobre el acceso a la información generada por la arqueología, considerando que es una forma de involucrarse en el proceso de manejo indígena del patrimonio. Asimismo, esta institución ha hecho pública su decisión de retirar los cuerpos humanos de la exhibición permanente (Declaración Pública IIAM, 04/09/2006), dando respuesta así a una de las demandas atacameñas manifestadas en los documentos entregados a la Comisión de la Mesa de Verdad Histórica y Nuevo Trato (2003). Para concretar la relocalización de los restos humanos de la exhibición, se constituyó un grupo de trabajo integrado por profesionales del Museo y representantes de la etnia atacameña, el cual continúa reuniéndose para afinar los detalles de este proceso.

Por otro lado, una de las relaciones más recientes de colaboración entre arqueólogos y atacameños se refiere a las asesorías en la evaluación de Proyectos

9 Este programa se desarrolla en el Museo de San Pedro de Atacama y ha sido financiado por el CMN, la CONADI y el Programa Orígenes/MIDEPLAN-BID. 
de Impacto Ambiental, lo cual no se ha realizado sin ciertos conflictos, ya que algunos dirigentes consideran que la sola presencia de sitios arqueológicos puede ser utilizada para rechazar un proyecto de inversión hotelera, a pesar de que el informe arqueológico es uno, entre varios, de los estudios solicitados en estos casos. En este sentido, se plantea "los arqueólogos del Museo están con nosotros en esta lucha o no están" (Tercera Mesa de Diálogo 2005), en circunstancias que algunas comunidades están en contra de la construcción de hoteles, y otras están dispuestas a negociar a cambio de beneficios económicos.

Asimismo, algunos investigadores han colaborado en el proceso de la constitución de comunidades atacameñas. En efecto, el reconocimiento estatal de las comunidades indígenas requiere que se cumplan ciertos requisitos, que pueden darse en forma conjunta o aisladamente, pero que la organización debe argumentar para su constitución como comunidad. Uno de ellos es "provenir de un mismo poblado antiguo, para lo cual algunos dirigentes atacameños han recurrido a información arqueológica, ya sea a partir de informes solicitados a arqueólogos que trabajan en la zona o en base a la recopilación de los antecedentes bibliográficos correspondientes. En este contexto, la información arqueológica es valorada y utilizada como una herramienta útil para argumentar la legitimidad de las comunidades atacameñas ante el Estado, ya sea apelando a la presencia de un sitio arqueológico que puede ser interpretado como "poblado antiguo" (p.e., pucara de Lasana) o discutiendo la definición de "poblado" en base al registro arqueológico, como en el caso de la comunidad de Taira.

Las repercusiones de este proceso de diálogo y colaboración son evidentes en la selección de los problemas y metodologías de trabajo en la arqueología atacameña, así como en la implementación de programas de difusión o participación de la comunidad local en proyectos de investigación (Núñez et al. 2002 Ms; Agüero et al. 2003 Ms; Ayala 2003; Ayala et al. 2003; Carrasco et al. 2003; Uribe y Adán 2003). Actualmente no se excavan cementerios prehispánicos en San Pedro de Atacama, aunque en ciertos proyectos en los que se han encontrado entierros esto se ha comunicado a la población local para decidir en conjunto cómo abordar esta situación, aplicándose nuevas metodologías de trabajo. La inserción de los sitios arqueológicos en el mercado turístico ha llevado a indígenas y arqueólogos a trabajar en conjunto, en circunstancias que algunas comunidades se muestran más abiertas a las investigaciones arqueológicas ya que creen que el hallazgo de sitios puede darles la posibilidad de acceder a los beneficios del turismo y con ello incrementar su capital económico.

Otra modalidad de interacción es la de delegar/intermediar, ya que el año 2004 el Museo de San pedro de Atacama creó un cargo en su planta profesional específicamente orientado a vincular a esta institución con la comunidad atacameña. Se trata de un mediador institucional que tiene a su cargo la ejecución y formulación de programas o acciones de difusión y la realización de charlas en las comunidades sobre temáticas relacionadas con la arqueología y el patrimonio. Junto con esto, este cargo gestiona instancias de conversación y negociación con los atacameños, además de encargarse de la participación institucional en reuniones y actividades organizadas por las comunidades atacameñas, en las cuales se solicita la presencia del Museo. A esta unidad llegan las solicitudes de asesoría profesional para proyectos de impacto ambiental o asesorías museológicas. Esta modalidad de relación también ha sido replicada en un proyecto de investigación (FONDECYT 1030931), que contaba con un profesional encargado de establecer el vínculo con los atacameños y difundir los resultados del proyecto.

Entre los arqueólogos se observan algunas críticas al respecto, sobre todo porque esta modalidad de interacción implica el establecimiento de relaciones indirectas:

\begin{abstract}
"Hoy día lo que se está haciendo en San Pedro es a partir de 'démosle el espacio a, pero que lo haga otro, nosotros brindamos la casa no más' y obviamente todo lo que tenga que ver con eso, pero para eso contratamos gente que lo haga" (Arqueólogo 9, 2004).
\end{abstract}

Si bien es cierto que se trata de una forma de relacionarse con el otro desde la exterioridad, hasta el momento la labor desarrollada a través de un intermediario ha sido bien acogida por las comunidades atacameñas e instituciones involucradas, ya que se tiene un interlocutor específico ante quien plantear inquietudes y solicitudes, aunque sin duda se trata de un tipo de relación en proceso de formación.

Como se puede apreciar, en este período iniciado con la promulgación de la Ley Indígena y con el 
fortalecimiento del discurso patrimonial de parte del Estado chileno, se diversifican las formas de interacción entre atacameños, arqueólogos y funcionarios estatales, ya que se identifican relaciones de negación, conocimiento, visibilización, colaboración, diálogo, negociación e intermediación.

\section{Conclusiones}

En este artículo se plantea que el proceso de patrimonialización en Chile se inicia a principios del Siglo XX con la creación del CMN, siendo reimpulsado con la promulgación de la Nueva Ley de Monumentos Nacionales en 1970. Desde esta fecha se consideran nuevas categorías de monumentos y se establece que los vestigios arqueológicos son Monumentos Arqueológicos sin la necesidad de ser declarados como tales. A mediados de los 90 comienza la consolidación del CMN, lo cual deriva en el fortalecimiento del discurso patrimonial a nivel nacional, así como en la mayor visibilidad y ampliación de la noción de patrimonio y la incorporación de la participación ciudadana. Desde este entonces, el Estado asume más claramente que nunca su rol protagónico en la definición, sistematización, institucionalización y control del patrimonio cultural del país.

En el contexto disciplinario de la arqueología atacameña se observan transformaciones a lo largo de su historia. Desde sus inicios la excavación de cementerios prehispánicos era una práctica recurrente en Atacama, pudiéndose situar su etapa de apogeo hasta finales de la década de los 70. Esto cambia en los años 80 al desarrollarse una arqueología profesional con nuevos enfoques, problemas y metodologías de estudio que reorientan el énfasis en la arqueología funeraria y el coleccionismo de momentos previos. El planteamiento de una continuidad histórica atacameña y la adscripción étnica del registro arqueológico forman parte del discurso construido por diferentes arqueólogos que han trabajado en la zona.

La apropiación y resignificación de los discursos patrimonial y arqueológico de parte de los atacameños se desarrolla a partir de su interacción histórica con arqueólogos, instituciones estatales y museales. Si bien a finales de los 80 ya se identifica una apropiación e instalación del discurso patrimonial en San Pedro de Atacama, es en el proceso de reivindicación étnica que adquiere alta visibilidad y es utilizado por dirigentes atacameños como recurso estratégico. En estas circunstancias, el patrimonio arqueológico y los discursos del pasado forman parte de los movimientos de reivindicación indígena como recurso simbólico, económico y político en el proceso de construcción y legitimación de la etnia atacameña ante el Estado y la sociedad chilena. Se plantea además que la patrimonialización étnica de la últimos años ha incidido en conflictos y reacomodos en las relaciones entre indígenas, arqueólogos y Estado, ya que los atacameños se constituyeron en otro actor social interesado en el patrimonio arqueológico, que reivindica sus derechos, manifiesta sus demandas y reclama su participación en la toma de decisiones al respecto, en circunstancias que años atrás era exclusivamente el Estado, en conjunto con los arqueólogos y otros especialistas, el que otorgaba sentido, protegía, controlaba y estudiaba el patrimonio. Con anterioridad a la promulgación de la Ley Indígena, no se contaba con un contexto político favorable ni con un sustento legal a partir del cual los atacameños plantearan sus demandas patrimoniales a los arqueólogos y al Estado.

A lo largo de los tres períodos se observa que las relaciones entre estos actores son dinámicas, ya que en un mismo período se activa más de una forma de interacción, las cuales pueden darse de forma sincrónica o diacrónica. Este dinamismo y fluctuación en las relaciones se desarrolla también en un solo sujeto, ya que un mismo dirigente atacameño, arqueólogo o funcionario estatal se relaciona de diferentes maneras a lo largo del tiempo y cambia sus posturas respecto al otro. En este caso, de relaciones de negación ciertos sujetos pasan a otras de conocimiento, colaboración y negociación o viceversa, ya que esto puede depender de los intereses que están en juego en determinado momento. En algunas ocasiones, arqueólogos cuya postura ha sido la de conocer y trabajar con las comunidades, en otras, con el fin de cumplir sus intereses profesionales niegan o desconocen los intereses indígenas. Asimismo, dirigentes que en su momento fueron la cara visible de posturas radicales, en la actualidad dialogan con los arqueólogos y las instituciones involucradas con el fin de alcanzar beneficios para su comunidad. Ciertamente, no se trata de un proceso en el cual las relaciones se transforman de la negación al conocimiento y la colaboración entre los actores, sino más bien de un complejo sistema de relaciones de diferente tipo, cuyos rumbos y giros son inciertos y difíciles de predecir.

Se evidencia, además, que las actuales relaciones entre los actores son el resultado de un proceso histórico 
de interacción, caracterizado por su dinamismo y por configurarse de manera distintiva y particular a lo largo del tiempo. Asimismo, los diferentes tipos de interacción identificados evidencian que, lejos de poder encasillar a los actores de este proceso en una de ellas, es necesario considerar que algunas de estas relaciones coexisten entre sí a lo largo del tiempo. Al respecto, cabe mencionar que las relaciones de negación, conocimiento mutuo y colaboración tienen antecedentes previos a la década de los 90, a diferencia de las de visibilización, diálogo/negociación e intermediación que, junto a las anteriores, se vinculan específicamente al contexto de emergencia étnica. Otra de las conclusiones de este trabajo es que las relaciones de negación del otro y el desconocimiento de sus significados culturales, valoraciones e intereses han sido las más vinculadas con los conflictos y la radicalización de los discursos entre arqueólogos, atacameños y el Estado, siendo clara una necesidad de conocer, visibilizar, dialogar, negociar, colaborar e intermediar con las poblaciones indígenas para la consolidación de relaciones más constructivas.

La investigación presentada en estas páginas no tiene el objeto de juzgar la forma en que se ha hecho o se hace arqueología en Atacama, sino dar cuenta de un proceso histórico de relaciones que nos lleve a construir una arqueología que no excluya a la sociedad en que se desarrolla. Esto no implica desconocer los objetivos de la arqueología y los avances que ha tenido, sino pensar nuestra realidad como ex colonias y países con poblaciones indígenas que continúan planteando demandas y críticas al quehacer arqueológico. Finalmente, es necesario considerar que nuestro papel como arqueólogos no radica en hablar por los otros, sino en hablar sin negar a los otros, en circunstancias que ninguna de estas voces debe ser silenciada.

Agradecimientos Debo mis sinceros agradecimientos a María Paniri, Felix Paniri, Cosme Mondaca, Vladimir Reyes, Carlos Aguilar, Santiago Ramos, Wilson Reyes, Teresa Aramayo, Rhony Gutiérrez, Cristián Pérez, Ricardo Tapia, Sandra Berna, Liliana Cortés, Aldo Barrales, Wilson Segovia, Angel Cabeza, César Millahueque, María Antonietta Costa, Agustín Llagostera, Lautaro Núñez, Ana María Barón, Victoria Castro, José Berenguer, Carlos Aldunate, Luis Cornejo, Mauricio Uribe, Gianina Stagno y a los alumnos de Escuela Andina. Agradezco también a Hans Gundermann y a Guillaume Boccara por sus comentarios a este escrito.

\section{REFERENCIAS CITADAS}

ADAN, L., 1996. Arqueología de lo cotidiano. Sobre diversidad funcional y uso del espacio en el Pucara de Turi. Memoria para optar al Título de Arqueóloga, Departamento de Antropología, Facultad de Ciencias Sociales, Universidad de Chile, Santiago.

AGÜERO, C., M. URIBE, L. ADAN y C. CARRASCO, 2003 Ms. Registro arqueológico y cronología del Período Formativo en los oasis de San Pedro de Atacama. Proyecto FONDECYT 1030931.

ALDUNATE, C. y V. CASTRO, 1981. Las chullpas de Toconce y su relación con el poblamiento altiplánico en el Loa Superior, Período Tardío. Ediciones Kultrun, Santiago.

ALDUNATE, C., V. CASTRO y V. VARELA, 2003. Oralidad y arqueología: Una línea de trabajo en las tierras altas de la región de Antofagasta. Chungara, Revista de Antropología Chilena 35 (2): 305-314.

AYALA, P., 2003. Arqueología y sociedad: El caso de las comunidades indígenas en Chile. Werken 4: 59-73.

2004. Discursos y actores en torno al patrimonio arqueológico: El caso atacameño. En VI Seminario sobre Patrimonio Cultural. Instantáneas locales, pp. 41-53, DIBAM, Santiago.
_2006. Relaciones y discursos entre atacameños, arqueólogos y Estado en Atacama (II Región, norte de Chile). Tesis para optar al Grado de Magíster en Antropología, Universidad Católica del Norte y la Universidad de Tarapacá, San Pedro de Atacama.

AYALA, P., S. AVENDAÑO y U. CARDENAS, 2003. Vinculaciones entre una arqueología social y la comunidad indígena de Ollagüe (Región de Antofagasta, Chile). Chungara, Revista de Antropología Chilena 35 (2): 275-285.

BENAVIDES, H., 2004. Los ritos de la autenticidad: Indígenas, pasado y el Estado ecuatoriano. Arqueología Sudamericana 1 (1): 5-48.

BERENGUER, J., C. ALDUNATE y V. CASTRO, 1984. Orientación orográfica de las chullpas en Likan: La importancia de los cerros en la Fase Toconce. Simposio Culturas Atacameñas, $44^{\circ}$ Congreso Internacional de Americanistas, pp. 175-220.

BRAY, T., 2001. American archaeologists and native Americans: A relationship under construction. En The future of the past: Archaeologists, native Americans, and repatriation, T. Bray (Ed.), pp. 1-8. Garland Publishing, Nueva York y Londres. 
CAPRILES, J., 2003. Arqueología e identidad étnica: El caso de Bolivia. Chungara, Revista de Antropología Chilena 35 (2): 347-353.

CASTRO V. (Ed.), 1995. Mesa de la generación de los 70. Boletín Sociedad Chilena de Arqueología, núm. especial: 13-27.

CASTRO, V. y F. GALLARDO, 1995-1996. El poder de los gentiles: Arte rupestre en el río Salado. Revista Chilena de Antropología 13: 79-98.

CARRASCO, C., C. AGÜERO, P. AYALA, M. URIBE y B. CASES, 2003. Investigaciones en Quillagua: Difusión del conocimiento arqueológico y protección del patrimonio cultural. Chungara, Revista de Antropología Chilena 35 (2): 321-326.

ENDERE, M. L., 2002. Management of archaeological sites and the public in Argentina. Thesis submitted to the University of London for the Degree of Doctor of Philosophy, Londres.

FERGUSON, T. J., 1996. Native American and the practice of archaeology. Annual Review in Anthropology 25: 63-79.

GNECCO, C., 1999. Archaeology and historical multivocality: A reflection from the Colombian multicultural. En Archaeology in Latin America, G. Politis y B. Alberti (Eds.), pp. 258-270. Routledge, Londres y Nueva York.

-2003 Ms. La colonización de la historia indígena por el discurso arqueológico. Ponencia presentada en el Simposio "Pueblos Originarios y Arqueología" del 51 Congreso Internacional de Americanistas, Santiago.

2004. Ampliación del campo de batalla. Textos Antropológicos 15 (2): 183-195.

GONZALEZ, J., 2002. Etología de camélidos y arte rupestre de la Subregión del río Salado (norte de Chile, II Región). Estudios Atacameños 23: 23-32.

GUNDERMANN, H., 1997. Etnicidad, identidad étnica y ciudadanía en los países andinos y el norte de Chile. Los términos de la discusión y algunas hipótesis de investigación. Estudios Atacameños 13: 9-26.

2002 Ms. Los atacameños de los siglos XIX y XX, una antropología histórica regional. Documento de trabajo interno de la Comisión de Verdad Histórica y Nuevo Trato, Grupo de trabajo Pueblos Indígenas del Norte, Subgrupo de trabajo Pueblo Atacameño.

2002. San Pedro de Atacama: Procesos, actores, imaginarios. En Retrato hablado de las ciudades chilenas, B. Guerrero (Ed.), pp. 45-62. Universidad Arturo Prat y Centro de Investigaciones Diego Barros Arana, Santiago.

GUNDERMANN, H. y H. GONZALEZ, 2005 Ms. Sociedades indígenas y conocimiento antropológico. Aymaras y atacameños de los siglos XIX y XX

JONES, S., 2000. The archaeology of ethnicity. Constructing identities in the past and present. Routledge, Londres $\mathrm{y}$ Nueva York.
KOONINGS K. y P. SILVA (Comps.), 1999. Construcciones étnicas y dinámica sociocultural en América Latina. Ediciones ABYA-YALA, Quito.

MERCADO, C., P. RODRIGUEZ y P. MIRANDA, 1997. Pa'que coman las almas. Chimuchina Records, LOM Ediciones, Santiago.

MIRANDA, P., 1997. Julián Colamar recuerda. Visiones de Caspana. LOM Ediciones, Santiago.

MORALES, H., 1997. Pastores transhumantes al fin del mundo. Un enfoque cultural de la tecnología en una comunidad andina de pastores. Memoria para optar al Título de Antropólogo, Departamento de Antropología, Facultad de Ciencias Sociales, Universidad de Chile, Santiago.

NAVARRO, X. (Comp.), 1998. Patrimonio arqueológico indígena en Chile, reflexiones y propuestas de gestión. Instituto de Estudios Indígenas, Universidad de la Frontera, UNESCO, Temuco.

NUÑEZ, L., 1995. Gustavo Le Paige s. j. Cronología de una misión. Ediciones Universitarias, Universidad Católica del Norte, Antofagasta.

NUÑEZ, L., I. CARTAJENA, C. CARRASCO y P. DE SOUZA, 2002 Ms. Transición del Arcaico Tardío al Formativo Temprano en la cuenca de Atacama: Emergencia de complejidad sociocultural en la Subárea Circumpuneña. Proyecto FONDECYT 1020316.

NUÑEZ, M., 2002. Transformaciones culturales en Toconao por impacto de empresas mineras: Un estudio de caso en el norte de Chile. Tesis para optar al grado de Magíster en Antropología y Desarrollo, Departamento de Antropología, Facultad de Ciencias Sociales, Universidad de Chile, Santiago.

ORELLANA, M., 1996. Historia de la arqueología en Chile (1842-1990). Colección Ciencias Sociales, Universidad de Chile, Santiago.

PREUCEL, R. e I. HODDER, 1996. Constructing identities. En Contemporary archaeology in theory, Part VII, Responses of "the others", R. Preucel e I. Hodder (Eds.), pp. 599-614. Blackwell Publishers, Londres.

RIVERA, F., 1997. Procesos de articulaciones socioidentitarias y reformulaciones étnicas en Atacama. Estudios Atacameños 13: 61-73.

ROMERO, A., 2003. Arqueología y pueblos indígenas en el extremo norte de Chile. Chungara, Revista de Antropología Chilena 35 (2): 337-346.

SALAZAR, D. y C. JIMENEZ, 1999. Epistemología y arqueología. De la urgencia por perder la inocencia. Boletín de la Sociedad Chilena de Arqueología 28: 31-36.

TRIGGER, B., 1980. Archaeology and the image of the American Indian. American Antiquity 45 (4): 662-676.

1984. Alternative archaeologies: Nationalist, colonialist, imperialist. Man, N. S. 19 (3): 355-370. 
1992. Historia del pensamiento arqueológico. Editorial Crítica, Barcelona.

URIBE, M., 1996. Religión y poder en los Andes del Loa: Una reflexión desde la alfarería (Período Intermedio Tardío). Memoria para optar al Título de Arqueólogo, Departamento de Antropología, Facultad de Ciencias Sociales, Universidad de Chile, Santiago.

URIBE, M. y L. ADAN, 2003. Arqueología, poblaciones originarias y patrimonio cultural en el Desierto de Atacama. Chungara, Revista de Antropología Chilena 35 (2): 295-304.
VARELA, V., 1992. De Toconce pueblo de alfareros a Turi pueblo de gentiles. Tesis para optar al Grado de Licenciado en Antropología con mención en Arqueología, Departamento de Antropología, Facultad de Ciencias Sociales, Universidad de Chile, Santiago.

VILLASECA, M. DE LOS A., 2000. Dos historias, un paisaje: Transformación y persistencia en el Alto Loa, Tesis para optar al Título de Antropóloga, Departamento de Antropología, Facultad de Ciencias Sociales, Universidad de Chile, Santiago. 